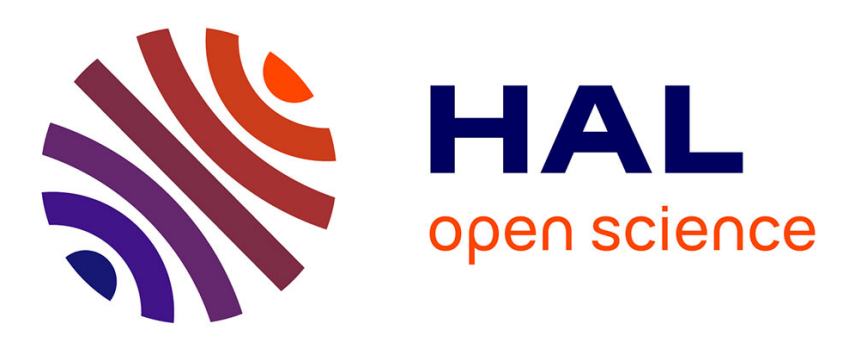

\title{
Behavioral Characterization, Potential Clinical Relevance and Mechanisms of Latent Pain Sensitization
}

\author{
Manon Gerum, Frédéric Simonin
}

\section{To cite this version:}

Manon Gerum, Frédéric Simonin. Behavioral Characterization, Potential Clinical Relevance and Mechanisms of Latent Pain Sensitization. Pharmacology \& Therapeutics, 2022, 233, pp.108032. hal03435269

\section{HAL Id: hal-03435269 \\ https://cnrs.hal.science/hal-03435269}

Submitted on 18 Nov 2021

HAL is a multi-disciplinary open access archive for the deposit and dissemination of scientific research documents, whether they are published or not. The documents may come from teaching and research institutions in France or abroad, or from public or private research centers.
L'archive ouverte pluridisciplinaire HAL, est destinée au dépôt et à la diffusion de documents scientifiques de niveau recherche, publiés ou non, émanant des établissements d'enseignement et de recherche français ou étrangers, des laboratoires publics ou privés. 


\section{Behavioral Characterization, Potential Clinical Relevance and Mechanisms of Latent Pain Sensitization}

Manon Gerum and Frédéric Simonin*

Affiliation : Biotechnologie et Signalisation Cellulaire, UMR7242 CNRS, Université de Strasbourg, Institut du Médicament de Strasbourg, Illkirch-Graffenstaden, France.

* Corresponding author:

Frédéric Simonin, Biotechnologie et Signalisation Cellulaire, UMR7242 CNRS / Université de Strasbourg, 300 boulevard Sébastien Brant, CS 10413, 67412 Illkirch-Graffenstaden, Cedex, France. +33-368854875; simonin@unistra.fr 


\section{Abstract}

Chronic pain is a debilitating disorder that can occur as painful episodes that alternates with bouts of remission and occurs despite healing of the primary insult. Those episodes are often triggered by stressful events. In the last decades, a similar situation has been evidenced in a wide variety of rodent models (including inflammatory pain, neuropathy and opioid-induced hyperalgesia) where animals develop a chronic latent hyperalgesia that silently persists after behavioral signs of pain resolution. This state, referred as latent pain sensitization, is due to the compensatory activation of antinociceptive systems, such as the opioid system or NPY and its receptors. A transitory phase of hyperalgesia can then be reinstated by pharmacological or genetic blockade of these antinociceptive systems or by submitting animals to acute stress. Those observations reveal that there is a constant endogenous analgesia responsible for chronic pain inhibition that might paradoxically contribute to maintain this maladaptive state and could then participate to the transition from acute to chronic pain. Thus, demonstration of the existence of this phenomenon in humans and a better understanding of the mechanisms by which latent pain sensitization develops and maintains over long periods of time will be of particular interest to help identifying new therapeutic strategies and targets for chronic pain treatment. The present review aims to recapitulate behavioral expression, potential clinical relevance, cellular mechanisms and intracellular signaling pathways involved so far in latent pain sensitization.

Keywords: latent pain sensitization - chronic pain - hyperalgesia - spinal cord - opioid - antiopioid 


\section{Abbreviations:}

AC1 : Adenylate Cyclase type 1; AMPA : $\alpha$-Amino-3-hydroxy-5-methyl-4-isoxazolepropionic acid ; $\alpha 2 \mathrm{~A}: \alpha 2$ Adrenergic; cAMP : cyclic adenosine monophosphate; CFA : Complete Freund's Adjuvant; CPEB : cytoplasmic polyadenylation element binding protein; CRF : Corticotropin Releasing Factor; DAMGO : D-Ala2, N-Me-Phe4, Gly5-ol]-Enkephalin acetate salt; DOR : Delta Opioid Receptor; Epac1 : Exchange Protein directly Activated by cAMP Type 1; Epac2 : Exchange Protein directly Activated by cAMP Type 2; ERK : Extracellular signal Regulated Kinase; IL-6 : interleukin-6; KOR : Kappa Opioid Receptor; MOR : Mu Opioid Receptor; NGF : Nerve Growth Factor; NMDA : N-Methyl-D-aspartate; NMDA-R : N-Methyl-D-aspartate Receptor; Nor-BNI : Nor-binaltorphimine; NPY : Neuropeptide Y; pERK : phospho Extracellular signal-Regulated Kinases; $\mathrm{PGE}_{2}$ : prostaglandin E2; PKA : Protein Kinase A; SFK

: Src Family Kinase; TLR4 : Toll Like Receptor 4; TRPA1 : Transient Receptor Potential Ankyrin 1; TRPV1 : Transient Receptor Potential Vanilloid type 1 


\section{Table of contents}

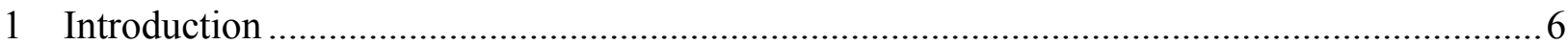

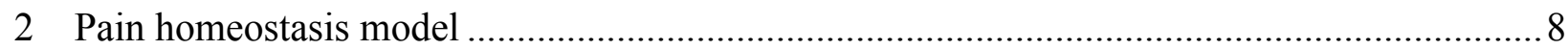

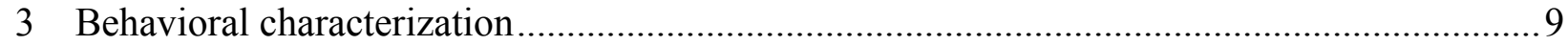

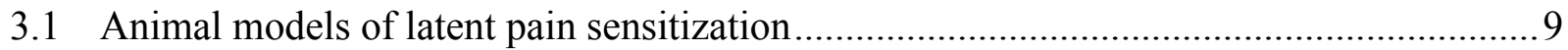

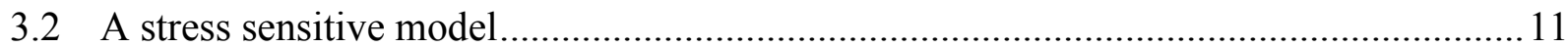

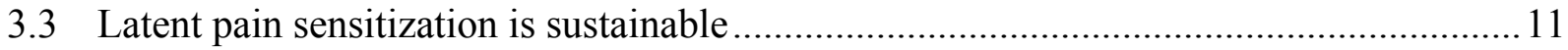

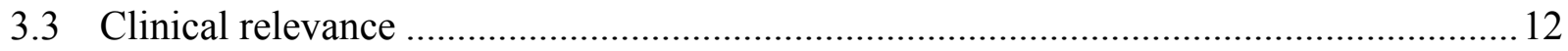

4 Spinal mechanisms of latent pain sensitization............................................................. 13

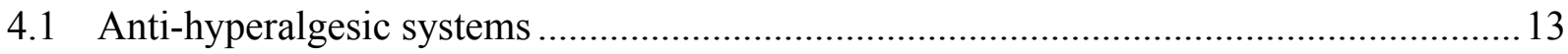

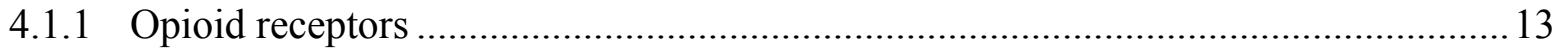

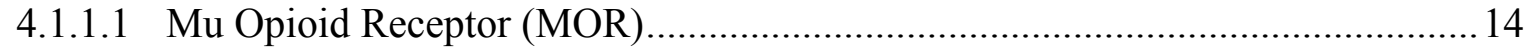

4.1.1.2 Delta Opioid Receptor (DOR) and Kappa Opioid Receptor (KOR) ................... 16

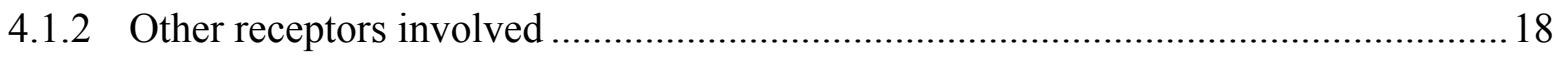

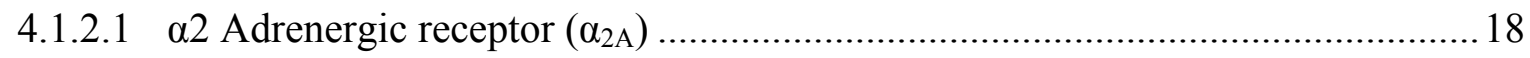

4.1.2.2 Neuropeptide Y (NPY) and its Y1 -Y2 receptors ........................................ 18

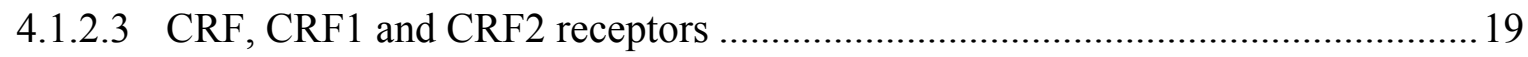

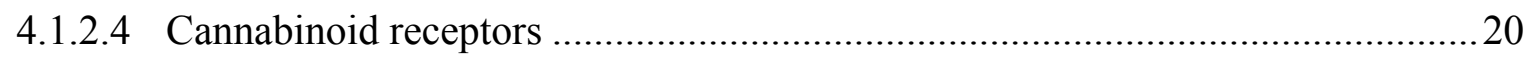

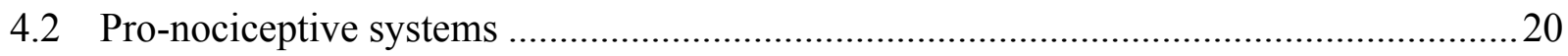

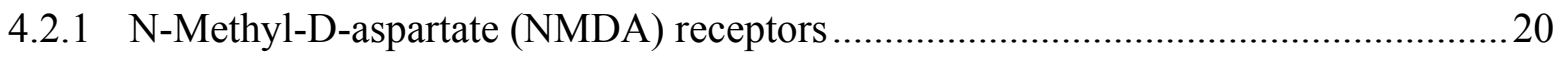




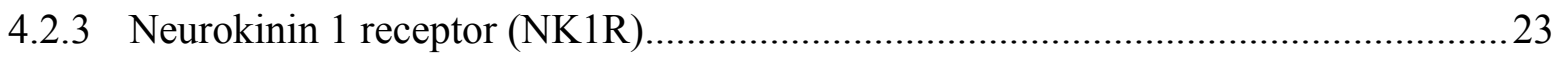

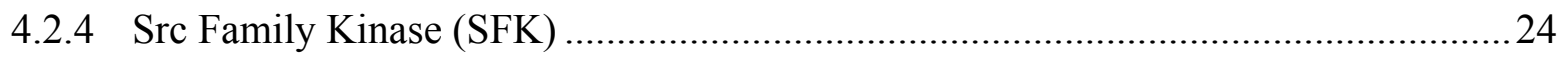

5 Supraspinal mechanisms of latent pain sensitization .................................................25

6 Peripheral mechanisms of latent pain sensitization......................................................25

6.1 Peripheral mechanisms considered as relevant for latent pain sensitization ...................25

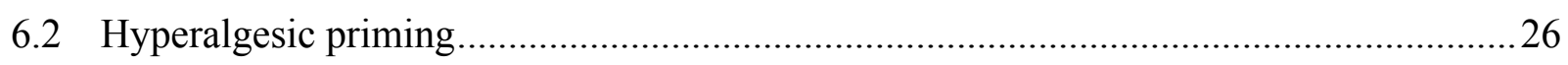

7 Non neuronal mechanisms of latent pain sensitization ................................................ 31

8 Other relevant factors in the establishment of latent pain sensitization............................... 32

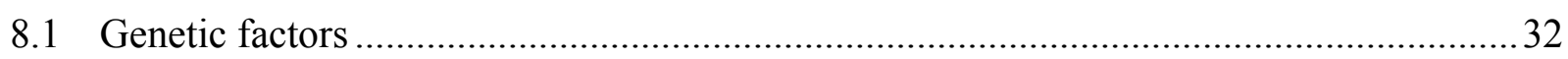

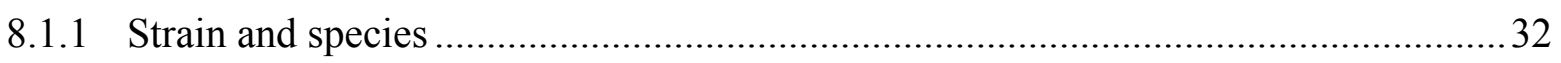

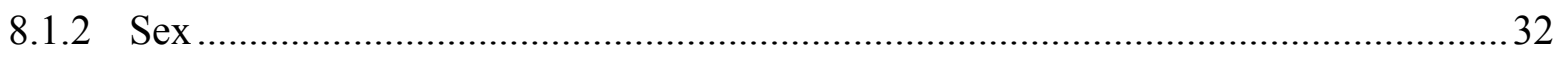

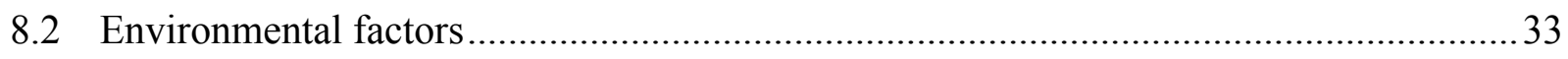

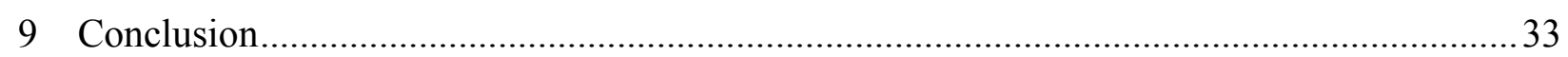

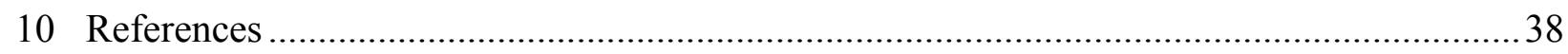




\section{Introduction}

In the last decades chronic pain disorders have become a major health care problem with $34 \%$ of the adult population suffering worldwide (Jackson et al., 2016). Chronic pain is defined as persisting beyond "normal" injury healing (Bonnica, 1953) which can be difficult to evaluate in some cases and was therefore considered chronic when lasting or recurring more than 3 months (Treede et al., 2015). Moreover, some types of chronic pain, such as low back pain (Cassidy et al., 2005), chronic neck pain (Nolet et al., 2010), migraine (Bigal \& Lipton, 2008), irritable bowel syndrome (Palsson et al., 2014), neuropathic and cancer pain (Mercadante et al., 2002), manifests as recurrent periods of pain that alternates with period of remission rather than a continuous prolonged state of pain. Those painful episodes can be triggered or intensified by acute stress (Alexander et al., 2009; Blanchard et al., 2008; Marmura, 2018). Those disorders are debilitating and regularly associated with sleep deprivation, depression, and anxiety (Emery et al., 2014). Opiates are the most powerful analgesics to alleviate acute pain, but prolonged exposure leads to severe adverse side effects including respiratory depression, addiction, tolerance, and opioid-induced hyperalgesia thus limiting the use of these compounds in the treatment of chronic pain (Angst \& Clark, 2006). In the US, the constant increase in opioid prescription for chronic pain over the last 15 years have led to a concomitant dramatic increase of death (Mattson et al., 2021) while several studies have shown that in humans chronic opioid treatments are often poorly effective (Chou et al., 2015). Concerning neuropathic pain, alternative first-line treatments exist, such as tricyclic antidepressant and serotonin-noradrenaline reuptake inhibitors (Attal, 2019) but they are also poorly efficient in the long-term. Novel therapeutic strategies for the treatment of chronic pain are therefore urgently needed.

In line with this statement, animal models of chronic pain have been developed to improve pain management and better understand pain chronification. It is now acknowledged that central sensitization, defined by the International Association for the Study of Pain as "an increased 
responsiveness of nociceptive neurons in the central nervous system to their normal or subthreshold afferent input" (Loeser \& Treede, 2008), contributes to development and maintenance of chronic pain. Different cellular processes including loss of inhibitory transmission, enhancement in membrane excitability and increased synaptic strength result in central sensitization (Latremoliere \& Woolf, 2009) but whether those neuroplastic changes are sustained after hyperalgesia disappearance to confer long-term pain susceptibility is unknown.

More recently, a new form of central sensitization, which silently persists following behavioral signs of pain has subsided, has been highlighted in various rodent pain models (Campillo et al., 2011; Célèrier et al., 2001; Corder et al., 2013). This so-called latent pain sensitization reproduces the episodic nature (Campillo et al., 2011) and sensitivity to stress (Rivat et al., 2007) that are characteristic for some types of human chronic pain (Bigal \& Lipton, 2008; Cassidy et al., 2005; Mercadante et al., 2002; Nolet et al., 2010; Palsson et al., 2014). This phenomenon is thought to be the result of a long-lasting up-regulation of pro-nociceptive systems that outlasts hypersensitivity resolution and is actively masked by anti-nociceptive systems activity. Consequently, whenever anti-nociceptive systems fail to repress the hyperalgesic state, a new transitory hyperalgesia state occurs (Célèrier et al., 2001). This way, latent pain sensitization confers a long-lasting vulnerability to subsequent noxious or stressful stimuli and could underlie the transition from acute to chronic pain. Latent pain sensitization could then represent both a model and a hypothesis of chronic pain development (Marvizón et al., 2015) so its study is particularly interesting. Yet, latent pain sensitization establishment and maintenance are still poorly understood. The present review focuses on the behavioral characterization of latent pain sensitization, its clinical relevance and current knowledge on the molecular and cellular mechanisms underlying this process. 


\section{Pain homeostasis model}

Latent pain sensitization was initially evidenced following prolonged exposure to heroin (Célèrier et al., 2001). Because hypersensitivity to pain is one of the symptoms of opioid withdrawal (Kim et al., 1990) and pro-nociceptive systems are responsible for heroin-induced hyperalgesia (Larcher et al., 1998; Laulin et al., 1998), Simonnet and colleagues evaluated their contribution to delayed hyperalgesia after opioid-induced hyperalgesia has resolved. Based on their results, the authors suggested that animals that returned to their pre-drug nociceptive threshold are in a new biological state where hyperalgesia is sustained but repressed by the endogenous activation of opioid system, which contribute to make it latent according to the process shown in Figure 1.

In their model, Célérier and collaborators hypothesized that the basal nociceptive threshold results from a homeostatic equilibrium between pro-nociceptive and anti-nociceptive systems activity (McNally, 1999; Rothman, 1992). In physiological conditions, both systems are balanced and poorly activated. This is the homeostatic state, responsible for the basal nociceptive threshold. Chronic opioids, inflammation, or neuropathy stimulate pro-nociceptive systems, which leads to a decrease of the nociceptive threshold (named hyperalgesia) that counteracts the net analgesic effect of the exogenous opioid, explaining apparent tolerance (progressive decrease of the analgesic properties caused by a repeated administration of a fixed dose of an opiate). When opioid treatment stops or the noxious stimulation resolves, the endogenous opioid system activates to counterbalance the sensitization of pro-nociceptive systems, according to the opponent-process theory (Simonnet \& Rivat, 2003) and animals return gradually to their basal nociceptive threshold until complete hyperalgesia resolution, so that pro- and anti-nociceptive systems are now equally and tonically active (allostasis). This state of allostasis is at equilibrium but differs from the initial homeostasis. Indeed, allostasis is a sustained state of hypersensitivity under the inhibitory control of anti-nociceptive systems. This pro-nociceptive system 
sensitization, qualified as latent, can be visualized by interfering with the balance and reveals the abnormal and persistent activation of the endogenous opioid system (Célèrier et al., 2001) and other anti-nociceptive systems, as it was demonstrated thereafter (Solway et al., 2011; Walwyn et al., 2016). In rodent, latent pain sensitization is usually assessed as it follows:

1) Exaggerated sensitivity to the same noxious stimulus, with an extended magnitude and/or duration of hyperalgesia or allodynia response compared to the first one (Bessière et al., 2007; Rivat et al., 2002, 2008).

2) Responsiveness to a non-noxious stimulus, manifested as a transitory phase of hyperalgesia following anti-nociceptive systems disruption, either pharmacologically or genetically (Campillo et al., 2011; Corder et al., 2013; Solway et al., 2011; Walwyn et al., 2016).

3) Responsiveness following a stimulus that normally induces analgesia, like stress (stress-induced hyperalgesia) or an ultra-low dose of opioid (Bessière et al., 2007; Le Roy et al., 2011; Rivat et al., 2007, 2008).

Importantly, pain sensitivity is not reinstated in naïve animals. This new equilibrium can be sustained for a long time after the nociceptive stimulation and confers a long-term vulnerability to new pain episodes. Therefore, latent pain sensitization could explain how pain switches from being acute to chronic and could represent a model for chronic pain disorders mechanisms (Marvizón et al., 2015).

\section{Behavioral characterization}

\subsection{Animal models of latent pain sensitization}

Latent pain sensitization was first evidenced in a model of chronic heroin treatment but the concept was rapidly generalized to other opioids including fentanyl (Laulin et al., 2002; Rivat et al., 2002), remifentanil (Cabañero et al., 2009), morphine (Lian et al., 2010; Roeckel et al., 2017) 
and D-Ala2, N-Me-Phe4, Gly5-ol]-Enkephalin (DAMGO; (Araldi et al., 2017)) in agreement with the pain homeostasis model (Célèrier et al., 2001).

Recently, latent pain sensitization was identified in other well-established models of persistent pain, as paw plantar incision (Campillo et al., 2011; Romero-Alejo et al., 2016b), nerve injury (Chen \& Marvizón, 2020a, 2020b; Fu et al., 2020; Solway et al., 2011), carrageenan- (Le Roy et al., 2011) or Complete Freund's Adjuvant (CFA)-induced inflammatory pain (Araldi et al., 2017; Chen et al., 2018b; Chen \& Marvizón, 2020a, 2020b; Corder et al., 2013; Feehan \& Zadina, 2019; Marvizón et al., 2015; Severino et al., 2018; Solway et al., 2011; Taylor et al., 2019; Walwyn et al., 2016) and Nerve Growth Factor (NGF) induced non-specific low back pain (Zhang et al., 2017). Thus, nociceptive inputs can also indirectly stimulate endogenous opioid system to initiate sustained latent sensitization to pain. More importantly, this indicates common mechanisms across different models of chronic pain, either elicited by noxious stimuli or exogenous opioid exposure. Interestingly, when nociceptive inputs and opioid exposure are combined, they seem to have synergistic effects. The combination carrageenan/fentanyl (Bessière et al., 2007; Laboureyras et al., 2009; Richebé et al., 2005; Rivat et al., 2007, 2008; Romero et al., 2011), fentanyl/plantar incision (Rivat et al., 2008) and remifentanil/plantar incision (Cabañero et al., 2009; Campillo et al., 2011; Romero et al., 2011, 2017) produced an enhanced temporary hyperalgesia during remission compared to the noxious stimuli alone. Hence, exogenous opioids facilitate the development of latent pain sensitization induced by nociceptive stimuli. Similar observations were made in a study using two opioids, where fentanyl-induced latent pain sensitization was enhanced by an ultra-low dose of morphine, incapable of inducing latent pain sensitization by itself (Laulin et al., 2002).

Finally, this latent sensitization to pain was also evidenced in models of irritable bowel syndrome (Lian et al., 2010) and ocular neuropathy (Kopruszinski et al., 2020), suggesting that 
the neuroadaptive processes leading to latent pain sensitization are not restricted to the somatic nociceptive system but also extend to the trigeminal and visceral nociceptive systems.

\subsection{A stress sensitive model}

According to the model suggested by G. Simonnet and colleagues (Célèrier et al., 2001), whenever this fragile balance is impaired, a new transitory phase of hyperalgesia ensues. The pharmacological blockade of anti-nociceptive receptors is usually used to disrupt this equilibrium, but some studies showed that stress leads to the same result. An environmental stress that consists in placing the animals in a new experiment room with bright light source, reinstated hyperalgesia in fentanyl- and carrageenan treated rats. The duration of this stressinduced hyperalgesia increases with the number of stress sessions. Importantly, the same stress procedure induces analgesia in naive rats that is prevented by administration of the general antagonist of opioid receptors naltrexone (Rivat et al., 2007). Altogether, those results indicate that acute stress modulates the equilibrium between pro- and anti-nociceptive systems in favour of pro-nociceptive systems to cause a new transitory phase of hyperalgesia. The mechanism by which stress interferes with this equilibrium is still elusive, but a recent study argues that stressinduced hyperalgesia is mediated by the release of Corticotropin Releasing Factor (CRF) that maintains behavioral signs of hypersensitivity (Chen et al., 2018b). Further studies are needed to confirm this hypothesis.

Additionally, a stress performed before the opioid or the inflammatory pain experience can facilitate long-term hypersensitivity to pain. Pre-stressed rats show an enhancement of carrageenan-induced hyperalgesia compared to non-stressed rats (Le Roy et al., 2011). This exaggerated inflammatory hyperalgesia was prevented by an administration of naltrexone before the stress, suggesting that stress induced-endogenous opioids release is sufficient to induce latent pain sensitization. Accordingly, the higher the number of stress sessions, the more the exacerbation of inflammatory pain (Le Roy et al., 2011). 


\subsection{Latent pain sensitization is sustainable}

The duration of latent pain sensitization has been studied in different preclinical models of pain. It has been demonstrated that behavioral signs of hypersensitivity can be reinstated by a pharmacological blockade of anti-nociceptive systems until 150 days after remission of a postoperative pain (Campillo et al., 2011) and 105 days after resolution of inflammatory pain (Corder et al., 2013). Likewise, stress-induced hyperalgesia is still present four months after the nociceptive stimuli (Rivat et al., 2007). Latent pain sensitization is therefore a long-lasting phenomenon, which episodic nature and sensitivity to stress are reminiscent of certain types of human chronic pain (Bigal \& Lipton, 2008; Cassidy et al., 2005; Mercadante et al., 2002; Nolet et al., 2010; Palsson et al., 2014).

\subsection{Clinical relevance}

As discussed in the previous section, stress-induced hyperalgesia can be compared to stressful events as a common trigger of a painful period in humans. Importantly, different types of human chronic pain can be episodic (Bigal \& Lipton, 2008; Cassidy et al., 2005; Mercadante et al., 2002; Nolet et al., 2010; Palsson et al., 2014), another specificity found in latent pain sensitization. Thus, a few studies used the general opioid receptor antagonist naloxone to investigate whether this process occurs in humans. A first study reported no naloxone-induced hyperalgesia following resolution of a first-degree burn (Pereira et al., 2013). This negative result was thought to be due to an insufficient dose of naloxone rather than an absence of latent pain sensitization in humans. Indeed, further investigation showed that hyperalgesia was effectively reinstated with a higher dose of naloxone using the same model (Pereira et al., 2015a). However, only 4 of 12 volunteers developed latent pain sensitization and those where the subjects that developed the largest hyperalgesia area induced by thermal injury. So latent pain sensitization would seem to occur in humans but only in "high sensitizers", underlining individual differences to pain. A large-scale study selected and compared if those "high 
sensitizers" are more susceptible to develop latent pain sensitization than "low sensitizers" (Springborg et al., 2016) but no difference could be systematically evidenced neither between naloxone and placebo infusion nor between "high" and "low" sensitizers (Springborg et al., 2020). Even if other receptors than opioid ones participate in latent pain sensitization and the use of naloxone here could be questioned, the authors also raised concerns concerning the heterogeneity of the cohort and pain model (cutaneous heat injury) used in this study. Altogether, these results suggest that if latent pain sensitization does occur in humans, it might be more difficult to evidence compared to rodents due to methodological issues. Indeed, these studies were performed on healthy subjects with experimentally-induced pain and the occurrence of latent pain sensitization in chronic pain patients has not been reported yet although a phase II clinical trial is currently ongoing to assess latent pain sensitization in postsurgical patients (Pereira et al., 2015b). Further studies are therefore needed to fully establish the existence of latent pain sensitization in Human and understand the link between this phenomenon and the mechanisms leading to pain chronicization.

\section{Spinal mechanisms of latent pain sensitization}

As latent pain sensitization is considered a silent form of central sensitization, most of the studies explored central mechanisms involved in this process.

\subsection{Anti-hyperalgesic systems}

\subsubsection{Opioid receptors}

The opioid system was the first identified to maintain endogenous analgesia during latent pain sensitization. Pharmacological blockade of opioid receptors with naloxone, a non-selective opioid receptor antagonist, precipitated hyperalgesia following chronic heroin exposure (Célèrier et al., 2001). Similar observations were made in fentanyl-treated rats (Laulin et al., 2002), postoperative pain (Campillo et al., 2011; Richebé et al., 2005; Romero et al., 2011, 2013, 2017; 
Romero-Alejo et al., 2016a, 2016b) and partial nerve injury (Guan et al., 2010). Taken together, these behavioral studies indicate that a sustained endogenous opioids release (in the spinal cord) provides long-lasting hyperalgesia relief and underlies latent pain sensitization.

\subsubsection{Mu Opioid Receptor (MOR)}

The contribution of each opioid receptor subtype to latent pain sensitization was then studied individually, beginning with MOR, the main target of exogenous opioids.

Global MOR knockout (KO) mice show only a partial recovery from CFA-induced hyperalgesia (Walwyn et al., 2016), confirming the hypothesis that MOR compensatory activation underlies remission from hyperalgesia (Célèrier et al., 2001). Additional experiments confirmed MOR sustained activity during latent pain sensitization and further argue that it is caused by an increase of its constitutive activity (Corder et al., 2013; Walwyn et al., 2016). Receptor constitutive activity is a specific conformational state with spontaneous receptor signaling in the absence of the endogenous ligand. Importantly, only inverse agonists can block constitutive activity, whereas ligand-induced activation of a receptor is blocked both by a neutral antagonist and an inverse agonist. Since opiates prolonged exposure is known to promote MOR constitutive activity in models of drug dependence (Meye et al., 2012; Wang et al., 2004), it was extensively studied in latent pain sensitization by using naltrexone that has been shown to display MOR inverse agonist activity (Wang et al., 2001). First, naltrexone but not the MOR neutral antagonist 6 6 -naltrexol reinstates pain sensitivity in CFA sensitized mice (Corder et al., 2013) and rats (Walwyn et al., 2016). Importantly, 6 $\beta$-naltrexol administration is sufficient to abolish naltrexone induced hyperalgesia (Corder et al., 2013; Walwyn et al., 2016). Prodynorphin, Pro-enkephalin, and Pro-opiomelanocortin KO mice recover from acute hyperalgesia and display « normal » latent pain sensitization as evidenced by a naltrexone challenge (Walwyn et al., 2016) indicating that in the absence of endogenous opioid peptides, MOR is still activated

to maintain long-lasting inhibition of hyperalgesia. Basal $\left[{ }^{35} \mathrm{~S}\right]$-guanosine 5 -[ $[\gamma$-thio]triphosphate 
$\left(\left[{ }^{35} \mathrm{~S}\right]-\mathrm{GTP} \gamma \mathrm{S}\right)$ binding dose-dependently decreases with the MOR selective inverse agonist $\beta$ funaltrexamine in the dorsal horn of CFA-sensitized mice (Corder et al., 2013), supporting MOR signaling in the absence of ligands. Besides, no MOR internalization (usually triggered by endogenous opioid release) was reported during remission in the spinal cord of CFA-treated rats (Walwyn et al., 2016). In the same model, spinal MOR immunoprecipitation shows increased phosphorylation in Src Family Kinase (SFK) and MOR-SFK recruitment by $\beta$-arrestin 2 is involved in the constitutive activity of this receptor (Walwyn et al., 2016). Finally, MOR inhibits voltage-gated $\mathrm{Ca}^{2+}$ channels in dorsal root ganglia neurons of CFA sensitized mice in a ligandindependent manner since it is disrupted with naltrexone but not $6 \beta$-naltrexol (Walwyn et al., 2016). Naltrexone-induced hyperalgesia after recovery from CFA administration was reproduced several times in different labs (Chen \& Marvizón, 2020a, 2020b; Corder et al., 2013; Feehan \& Zadina, 2019; Severino et al., 2018; Taylor et al., 2019; Walwyn et al., 2016) and then extended to chronic morphine (Roeckel et al., 2017) and postoperative (Feehan \& Zadina, 2019) pain models. Naltrexone also induces signs of spontaneous and affective pain as assessed by the grimace scale score and conditioned place preference paradigm (Corder et al., 2013). Those results support the hypothesis that MOR long-lasting signaling is sustained by its constitutive activity in a model latent pain sensitization and that its involvement is not restricted to the sensory component of pain. However, a recent study reported that MOR selective antagonist CTOP (D-Phe-Cys-Tyr-D-Trp-Orn-Thr-Pen-Thr-NH $\mathrm{N}_{2}$ ) can dose-dependently reveal latent pain sensitization in a model of postsurgical pain induced by a plantar incision (Custodio-Patsey et al., 2020), suggesting that endogenous opioids release might also account in MOR sustained activation. Further experiments in different models of latent pain sensitization are now necessary to test this hypothesis.

MOR is broadly expressed throughout the nociceptive pathway, including supraspinal areas of pain integration (Mansour et al., 1995), central terminals of primary afferents and LI-LII of the 
dorsal horn spinal cord (Besse et al., 1990; Kohno et al., 1999). In order to investigate in which region of the central nervous system MOR is important for latent pain sensitization, mice genetically engineered to decrease MOR expression in primary afferents were shown to display weak pain reinstatement by naltrexone following CFA-induced hyperalgesia resolution (Severino et al., 2018). This result suggests that MOR located on primary nociceptors is important for the establishment and/or maintenance of latent pain sensitization, but it does not allow to discriminate between MOR expressed on central or peripheral terminals. A few lines of evidence suggests that MOR expressed on central terminals could be involved since peripherally restricted MOR antagonists reinstate hypersensitivity during remission when they are administered intrathecally but not subcutaneously (Campillo et al., 2011; Corder et al., 2013). Besides, hypersensitivity is bilaterally reinstated when MOR is pharmacologically blocked or either with stress-induced hyperalgesia (Corder et al., 2013; Rivat et al., 2007), indicative of central mechanisms. Studies specifically designed to address this question are needed.

\subsubsection{Delta Opioid Receptor (DOR) and Kappa Opioid Receptor (KOR)}

Because DOR and KOR are also expressed on supraspinal sites involved in pain modulation (Mansour et al., 1995), on central terminals of nociceptors and in the dorsal horn spinal cord (Besse et al., 1990; Kohno et al., 1999), their role in latent pain sensitization was investigated.

The DOR selective antagonist naltrindole reinstates a slight transitory phase of hyperalgesia in CFA inflammatory pain model in rats either injected subcutaneously or intrathecally (Walwyn et al., 2016). Subcutaneous naltrindole induced-hypersensitivity is more robust in CFA

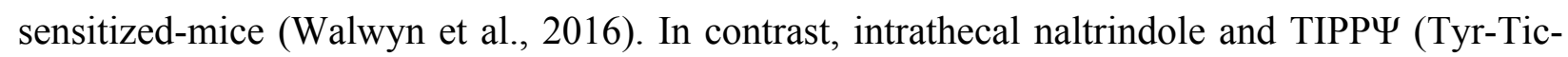
Phe-Phe $\Psi$, another DOR antagonist) reinstated mechanical hyperalgesia in paw incision model in mice only at high doses that induce adverse side effects (Custodio-Patsey et al., 2020) so that off-target effects cannot be excluded. More studies are required to determine whether DOR contributes to delayed hyperalgesia inhibition responsible for latent pain sensitization. 
The effectiveness of a subcutaneous injection of KOR antagonist nor-binaltorphimine (norBNI) to precipitate hypersensitivity in mice that had recovered from postsurgical pain (Campillo et al., 2011) indicates that KOR might also be involved in latent pain sensitization. In a CFA inflammatory pain model, hyperalgesia reinstatement by intrathecally administered nor-BNI in rats and subcutaneously administered JTiDC in mice has also been reported (Walwyn et al., 2016). Similar results were found with LY2456302, another KOR antagonist recently characterized (Rorick-Kehn et al., 2013, 2015). When intrathecally delivered during the remission state, it induces not only dose-dependent pain hyperresponsiveness but also increases touch-evoked phospho-Extracellular signal-Regulated Kinases (pERK) expression (a central sensitization hallmark) in LI-LII and LII-LV neurons of paw incision-sensitized mice (CustodioPatsey et al., 2020). Therefore, KOR mediated suppression of hyperalgesia is common to different chronic pain models, further supporting its anti-nociceptive role in latent pain sensitization. More studies are warranted to determine if only KOR localized in the spinal cord are involved or if supraspinal and peripheral KOR also participate to this process. Nevertheless, KOR-mediated signaling during latent pain sensitization is still unknown. Genetically deficient Pro-dynorphin mice display "normal" behavioral hypersensitivity following subcutaneous administration of JDTiC, suggesting that KOR contributes to latent pain sensitization even in the absence of dynorphin (Walwyn et al., 2016). In line with this observation, no increase in spinal dynorphin levels was reported following subcutaneous naloxone injection in mice that had recovered from postoperative pain (Campillo et al., 2011). It is therefore unlikely that KOR signaling during the remission state is due to a release of dynorphin. KOR might act via an increase of its constitutive activity, but further experiments designed to address this specific question are required. 


\subsubsection{Other receptors involved}

\subsubsection{1 $\quad \alpha 2$ Adrenergic receptor $\left(\alpha_{2 \mathrm{~A}}\right)$}

Noradrenergic descending pathways mediate analgesic effects through $\alpha_{2 \mathrm{~A}}$ receptors (Pertovaara, 2006) expressed in central terminals of primary afferents (Stone et al., 1997). Their contribution to sustained hyperalgesia suppression was then evaluated. A few studies showed reinstatement of transitory hyperalgesia with $\alpha_{2 \mathrm{~A}}$ receptor antagonist BRL44408 administered intrathecally in rats (Walwyn et al., 2016) and subcutaneously in mice (Severino et al., 2018; Walwyn et al., 2016), suggesting that spinal $\alpha_{2 \mathrm{~A}}$ receptors exert a tonic inhibitory control responsible for latent pain sensitization, but involvement of supraspinal and peripheral receptors cannot be excluded.

\subsubsection{Neuropeptide $\mathrm{Y}(\mathrm{NPY})$ and its Y1 -Y2 receptors}

NPY and its Y1 and Y2 receptors are expressed in the dorsal root ganglia and the dorsal horn of the spinal cord (Brumovsky et al., 2005; Gibson et al., 1984; Kopp et al., 2002). This neuropeptide shows anti-nociceptive activities (Intondi et al., 2008) and is upregulated following nerve damage and inflammation in the dorsal root ganglia (Wakisaka et al., 1992) for 24 weeks (Intondi et al., 2010), making NPY a potential candidate for opposing long-lasting hyperalgesia during latent pain sensitization.

Using genetic approaches, Taylor and colleagues showed that conditional NPY depletion in the dorsal root ganglia and the dorsal horn precipitates behavioral hypersensitivity in CFA and nerve-injured sensitized mice. An intrathecal injection of NPY was sufficient to reverse this transitory hyperalgesic state (Solway et al., 2011). In accordance with these results, intrathecally administered Y1 and Y2 receptors antagonists (BIBO3304 and BIIE0246, respectively) reveal latent hyperalgesia dose-dependently in the same model (Solway et al., 2011). Taken together, those results confirm that NPY-Y1 and NPY-Y2 signaling in the spinal cord exert a sustained inhibitory pain control after the resolution of injury. This signaling is likely mediated by an 
endogenous NPY release within the spinal cord that activates spinal Y1 and Y2 receptors. Whether NPY is released by the dorsal root ganglia or the descending inhibitory pain control needs to be clarified. NPY seems also to repress hallmarks of central sensitization. Y2 (but not Y1) antagonist induces pERK and c-fos upregulation in LI-LII spinal laminae following CFAinduced hyperalgesia resolution (Solway et al., 2011), confirming its role as an anti-nociceptive system. Finally, NPY involvement in latent pain sensitization is not restricted to nociception and extends to the unpleasant and uncomfortable component of pain, as assessed by the conditioned place aversion produced by an intrathecal administration of Y1 antagonist and in NPY conditional knock-down (Fu et al., 2020).

\subsubsection{CRF, CRF1 and CRF2 receptors}

Because acute stressors display hyperalgesic properties in animals with latent pain sensitization, the contribution of CRF and its receptors, which are important mediators of the stress response, were studied.

Mice genetically deleted for CRF1 receptor subtype showed an enhanced naloxone-induced hyperalgesia compared to wild type littermates in a model of postsurgical pain (Romero et al., 2017) indicating that CRF1 is part of the anti-nociceptive systems providing long-lasting suppression of hyperalgesia. Another study showed that an intracerebroventricular injection of CRF reinstates behavioral signs of pain in CFA-sensitized rats (Chen et al., 2018b). Therefore, stress-induced hyperalgesia during latent pain sensitization might be due to a release of CRF, which is inconsistent with the anti-hyperalgesic properties of CRF1 receptor. Opposite effects of $\mathrm{CRF}$ on its CRF1 and CRF2 receptors have been reported in amygdala neurons (Fu \& Neugebauer, 2008; Ji \& Neugebauer, 2008; Rouwette et al., 2012). The CRF pro-nociceptive effect observed by Marvizon and colleagues (Chen et al., 2018b) could therefore be mediated via CRF2 receptors in the amygdala. Further investigations are required to distinguish the respective 
role of CRF1 and CRF2 receptor subtypes and explore the potential interaction between opioid and CRF systems during latent pain sensitization.

\subsubsection{Cannabinoid receptors}

Cannabinoids are used in some cases to provide migraine pain relief (Baron, 2015). A recent study evaluated their ability to induce paradoxical long-term pain vulnerability just like opioids. In a model of medication overuse headache, the cannabinoid 1 receptor agonists WIN55,212-2 (full agonist) and $\Delta$-9-Tetrahydrocannabinol (partial agonist) were shown to cause latent pain sensitization as assessed by bright light stress-induced hyperalgesia following headache resolution (Kopruszinski et al., 2020).

\subsection{Pro-nociceptive systems}

\subsubsection{N-Methyl-D-aspartate (NMDA) receptor}

As NMDA receptors were already identified as a pro-nociceptive system responsible for opioid-induced hyperalgesia (Célèrier et al., 1999, 2000; Larcher et al., 1998; Laulin et al., 1998), its involvement in latent pain sensitization was quickly investigated.

Pre-emptive blockade of NMDA receptor with MK-801 prevents delayed hyperalgesia induced by chronic heroin treatment (Célèrier et al., 2001). Ketamine pretreatment partially blocks naloxone-precipitated hyperalgesia in fentanyl-treated rats (Laulin et al., 2002) and fentanyl enhancement of carrageenan-induced hyperalgesia (Richebé et al., 2005; Rivat et al., 2002). In the same model, ketamine, BN2572 (a NMDA antagonist) and $\mathrm{N}_{2} \mathrm{O}$ (a gas with antiNMDA properties) also prevent stress-induced hyperalgesia (Bessière et al., 2007, 2010; Rivat et al., 2007). Exaggerated hyperalgesia in pre-stressed rats is in part prevented by NMDA antagonists ketamine and BN2572 (Le Roy et al., 2011). Lastly, a polyamine deficient diet (that negatively modulates NMDA receptors activity) prevented hyperalgesia exacerbation induced by a second inflammation and stress-induced hyperalgesia in pain and opioid experienced rats (Rivat et al., 2008). Interestingly, a polyamine deficient diet not only opposed the development 
of latent pain sensitization but also reverses it. Indeed, stress-induced hyperalgesia was blocked in rats fed with a polyamine deficient diet right after carrageenan-induced hyperalgesia has resolved (Rivat et al., 2008). Consequently, NMDA receptor activation was found across different models of latent pain sensitization using various strategies aiming to decrease or abolish its signaling, which supports its role as a pronociceptive system that silently maintains the hyperalgesic state during remission.

The NMDA receptor signaling pathway was then characterized by Corder an collaborators in their model of CFA-induced latent pain sensitization in mice (Corder et al., 2013). They demonstrated that NMDA receptor elicits an Adenylate Cyclase type 1 (AC1)-dependent pathway under the tonic inhibitory control of MOR (Figure 2 middle panel). During the posthyperalgesic state, naltrexone increases glutamate-evoked intracellular $\mathrm{Ca}^{2+}$ in the spinal cord, which is abolished by MK-801, indicating that this rise in $\mathrm{Ca}^{2+}$ is NMDA-dependent. In the same way, naltrexone-mediated cyclic adenosine monophosphate (cAMP) upregulation in the spinal cord is blocked by MK-801 in CFA-sensitized mice, suggesting that NMDA receptor activation leads to a spinal cAMP increase. This NMDA-cAMP pathway is mediated by AC1, since intrathecally delivered NMDA and forskolin increase nociceptive behaviors and cAMP overshoot in the spinal cord. In line with these results, the genetic deletion or pharmacological inhibition of $\mathrm{AC} 1$ prevents both naltrexone induced hyperalgesia and cAMP upregulation in the spinal cord. Altogether, those experiments demonstrate that MOR represses behavioral hypersensitivity via a tonic inhibition of a NMDA receptor (NMDA-R) $\rightarrow \mathrm{Ca}^{2+} \rightarrow \mathrm{AC} 1$ cAMP pathway in the spinal cord (Figure 2 lower panel).

More recent studies showed that the molecular pathway under the inhibitory control of the NPY / Y1 receptor system also comprises NMDA receptor. Unmasking CFA-induced latent pain sensitization with the Y1 antagonist is prevented by MK-801, AC1 inhibitor, Protein Kinase A (PKA) inhibitor, Transient Receptor Potential Ankyrin 1 (TRPA1) and Transient Receptor 
Potential Vanilloid type 1 (TRPV1) channel blockers, and by inhibitors of Exchange Protein directly Activated by cAMP Type 1 (Epac1) and type 2 (Epac2) (Fu et al., 2019). Latent pain sensitization was also absent in genetically deficient AC1 mice, leading the authors to conclude that NPY acts on Y1 receptors to tonically silence NMDA-R $\rightarrow \mathrm{AC1} \rightarrow \mathrm{PKA} \rightarrow \mathrm{TRPA} 1 /$ TRPV1 at the central terminals of nociceptors (Figure 2 middle panel) and NMDA-R $\rightarrow$ AC1 Epac1/2 pathways in NPY receptor-expressing interneurons in the dorsal horn (Figure 2 lower panel). Accordingly, PKA and Epac activators increase pERK immunoreactivity in the dorsal horn, and precipitate the hyperalgesic state, so that PKA and Epac are sufficient to reveal latent pain sensitization ( $\mathrm{Fu}$ et al., 2019). Downstream effectors of Epac1/2 remain to be identified. This NMDA-R - TRPA1 / TRPV1 signaling pathway is also involved in affective pain dimension reinstatement. Indeed, conditioned place aversion induced by Y1 antagonist or in NPY conditional knock-down mice is blocked by MK-801, AC1 inhibitor, TRPA1, and TRPV1 channel blocker and is absent in AC1 -/- mice in a model of nerve injury (Fu et al., 2020).

These results go further than previous findings of Corder and collaborators (Corder et al., 2013) and extend them to the neuropathic pain model. NMDA-R-AC1 pathway is involved in various models of latent pain sensitization, in both sensory and emotional aspects of pain and is silenced by MOR and Y1 receptor, making this cascade a key component of latent pain sensitization. This raises the possibility that other anti-nociceptive receptors might repress this pathway during the remission state. Notably, MK-801 prevented nor-BNI induced-hyperalgesia in a postsurgical incision pain model (Romero et al., 2011), suggesting that NMDA-R-AC1 might also be under the inhibitory control of KOR.

\subsubsection{Calcium permeable AMPA receptor}

As numerous studies demonstrated an upregulation of spinal calcium-permeable AMPA receptor in the early onset of acute pain in different pain models (Cabañero et al., 2013; Chen et al., 2013; Wigerblad et al., 2017), its contribution once hyperalgesia has resolved was explored. 
Supported by electrophysiological and calcium imaging experiments, an increase of AMPA receptor-induced $\mathrm{Ca}^{2+}$ permeability in the LII neurons has been reported in a CFA inflammatory pain model (Taylor et al., 2019). This AMPA receptor plasticity is silenced by MOR, as blockade of MOR by naltrexone increases AMPA-receptor mediated $\mathrm{Ca}^{2+}$. Consistent with these observations, IEM-1460 (a calcium-permeable AMPA-receptor antagonist) dose-dependently blocked naltrexone induced hyperalgesic state (Taylor et al., 2019). Therefore, AMPA receptorinduced $\mathrm{Ca}^{2+}$ permeability enhances synaptic strength in LII neurons and begets long-lasting hypersensitivity to pain that is masked by the inhibitory control of MOR. Mechanisms by which MOR drives AMPA receptor plasticity are still unknown.

\subsubsection{Neurokinin 1 receptor (NK1R)}

NMDA receptor, adenylate cyclase and protein kinase A, three key elements that contributes to latent pain sensitization (Célèrier et al., 2001; Corder et al., 2013; Fu et al., 2019) are also known to mediate substance $\mathrm{P}$ release by primary afferent fibers in the spinal cord dorsal horn (Chen et al., 2018a; Marvizón et al., 1997). Besides, presynaptic MOR inhibits substance P release (Chen et al., 2018a) and is responsible for endogenous analgesia in latent pain sensitization (Chen \& Marvizón, 2020a, 2020b; Corder et al., 2013; Feehan \& Zadina, 2019; Roeckel et al., 2017; Severino et al., 2018; Walwyn et al., 2016). Indeed, loss of MOR in central terminal of primary afferents in Nav1.8cre/flMOR mice abolished both MOR inhibition of NMDA receptor induced substance P release and latent pain sensitization (Severino et al., 2018). Altogether, these experiments indicate that NK1R activation by substance $\mathrm{P}$ might also be involved in latent pain sensitization.

A study tested this hypothesis using RP67580, a NK1R antagonist, in CFA or tibial spared nerve injury pain models (Chen \& Marvizón, 2020b). Blockade of naltrexone-induced allodynia was maintained 5 days after the last administration of RP6758NK1R suggesting that NK1R is not only involved in the expression but also in the maintenance of latent pain sensitization. 
Substance P release, measured in situ as NK1R internalization in spinal cord laminae I, was shown to be higher in CFA-sensitized rats than in control rats and was increased by naltrexone administration in the posthyperalgesic state (Chen \& Marvizón, 2020b). In accordance with a previous study (Severino et al., 2018), those results confirm that substance P mediates hyperalgesia during latent pain sensitization via NK1R that is repressed by MOR activation in primary afferent fibers (Figure 2 middle panel).

\subsubsection{Src Family Kinase (SFK)}

NMDA receptors are modulated and phosphorylated by SFK (Abe et al., 2005; Chen et al., 2010; Guo et al., 2002) a process that was shown to be critical in models of chronic pain (Appel et al., 2017; Hildebrand et al., 2016; Lai et al., 2016), so that involvement of SFK in latent pain sensitization was explored. Naltrexone-induced hyperalgesia was eliminated $15 \mathrm{~min}$ after a single intrathecal administration of PP2 (a SKF inhibitor) and 5 days following a 3 daystreatment with PP2. Thus, blockade of naltrexone-induced hyperalgesia is long lasting, suggesting that SFK contributes to both expression and maintenance of latent pain sensitization. Similar results were obtained with CFA- and spare nerve injury-induced latent pain sensitization, indicating common mechanisms across these different models (Chen \& Marvizón, 2020a). Of note, the combination of Src and MAPK inhibitors (SU 6656 and U0126 respectively) suppresses CFA-induced latent pain sensitization expression when co-administered with naltrexone. The effect of a Src inhibitor alone was not evaluated in this study (Araldi et al., 2017). Finally, co-immunoprecipitation of SFK with MOR show higher levels of SFK in the spinal cord of CFA sensitized rats compared to unsensitized animals (Walwyn et al., 2016), indicating that SKF signaling pathway might be recruited by MOR during latent pain sensitization. Further studies are needed to confirm this hypothesis and contribution of other receptors than MOR remains to be determined. 


\section{Supraspinal mechanisms of latent pain sensitization}

Most of the research mentioned above focuses on neuroadaptive processes occurring in the spinal cord. However, numerous experiments noticed pain reinstatement on both ipsilateral and contralateral paws (Bessière et al., 2007; Corder et al., 2013; Laboureyras et al., 2009; Rivat et al., 2002, 2007) indicating that descending inhibitory controls might be necessary to maintain the suppression of hyperalgesia. In agreement with this hypothesis, spinal blockade of descending inhibitory controls precipitates hyperalgesia bilaterally in CFA-sensitized rats (Chen et al., 2018b). This does not exclude the participation of descending facilitatory controls but further studies are needed to determine precisely which pathway is involved. Of note, naloxone causes glucose metabolism changes in the pain matrix in a postoperative pain model, especially in opioid-related pathways (Romero et al., 2011), suggesting that latent pain sensitization induces long-lasting neuroplastic adaptations both in spinal and supraspinal areas.

\section{Peripheral mechanisms of latent pain sensitization}

\subsection{Peripheral mechanisms considered as relevant for latent pain sensitization}

Several studies also argue that peripheral mechanisms might be considered in latent pain sensitization maintenance. In a model of partial nerve injury, systemic or intraplantar administration of naloxone methiodide (opioid receptors antagonist that does not cross the blood brain barrier) induces a transitory phase of allodynia (Guan et al., 2010). Similarly, intradermal administration of naloxone reinstates the hyperalgesic state in animals that received at the same site intradermal repeated administrations of DAMGO (Araldi et al., 2017). Then, it seems like peripheral opioid receptors might also participate in latent pain sensitization, but which opioid receptor(s) is (are) contributing in latent pain sensitization remains to be determined. It is unlikely that peripheral MOR are involved as only intrathecally (and not subcutaneously) administered peripherally-restricted MOR antagonists precipitate behavioral signs of pain during 
remission (Campillo et al., 2011; Corder et al., 2013). Involvement of KOR and DOR and maybe other receptors in latent pain sensitization needs to be confirmed.

\subsection{Hyperalgesic priming}

Another form of chronic latent hypersensitivity to pain referred to as hyperalgesic priming involves primary nociceptors and shares some features with latent pain sensitization. It was originally found in inflammatory mediated pain models and largely characterized (for review, see (Kandasamy \& Price, 2015; Reichling \& Levine, 2009). Hyperalgesic priming type I was defined by Levine and collaborators as "a neuroplastic change in the primary afferent nociceptor that causes prostaglandin E2 $\left(\mathrm{PGE}_{2}\right)$-induced hyperalgesia to last at least $24 \mathrm{~h}$ and to become dependent on Protein Kinase C epsilon (PKCE) " (Reichling \& Levine, 2009). Indeed once carrageenan-induced hyperalgesia has resolved, administration of an inflammatory cytokine $\mathrm{PGE}_{2}$ in the same paw is able to induce a 24h-hyperalgesia while the same $\mathrm{PGE}_{2}$-induced hyperalgesia lasts less than $4 \mathrm{~h}$ in naïve animals (Aley et al., 2000). Similarly, hyperalgesic priming can also be induced by interleukin-6 (IL-6; (Dina et al., 2008)), the 5-HT $1 \mathrm{~B} / \mathrm{D}$ agonist sumatriptan (Araldi et al., 2016b), high and low doses of morphine (Ferrari et al., 2019), NGF and Glial cell-Derived Neurotrophic Factor (GDNF; (Ferrari et al., 2010) and can be reinstated with serotonin and A2 receptor agonists (Aley et al., 2000).

This primed state is linked with changes in intracellular signaling pathways. $\mathrm{PGE}_{2}$ activates PKA via AC in naïve animals, since it is attenuated by PKA antagonist (Aley \& Levine, 1999). However in primed animals, $\mathrm{PGE}_{2}$ additionally stimulates $\mathrm{AC}$ to induce cAMP production (Parada et al., 2005) and Epac recruitment, which in turn activates PKCE (Hucho et al., 2005). Thus, $\mathrm{PGE}_{2}$ (Dina et al., 2009) and other receptors of inflammatory mediators, switch from inhibitory $\mathrm{G}$ to stimulatory G-coupled protein (Khasar et al., 2008). $\mathrm{PGE}_{2}$ also stimulates phospholipase $\mathrm{C} \beta$ (Joseph et al., 2007), which can in turn activate PKC $\varepsilon$. 
$\mathrm{PKC} \varepsilon$ is mandatory for hyperalgesic priming maintenance, as $\mathrm{PGE}_{2}$ induced hyperalgesia is

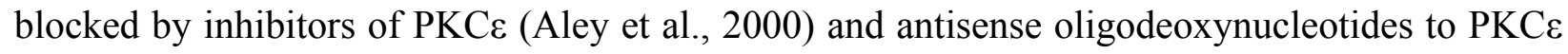
(Parada et al., 2003b). Conversely, PKC $\varepsilon$ is sufficient to express and maintain the primed state since its agonist $\psi \varepsilon \mathrm{RACK}$ is also able to induce hyperalgesic priming (Aley et al., 2000), even at low doses incapable to trigger the primary hyperalgesia (Parada et al., 2003b). The selective lesion of isolectin B4-positive nociceptors (a subtype of small diameter C-fibers) abrogates $\mathrm{PGE}_{2}$ reinstatement of hyperalgesia (despite $\psi \varepsilon R A C K$-induced hyperalgesia) suggesting that the switch in signaling pathway underlying hyperalgesic priming occurs in those neurons (Joseph \& Levine, 2010).

Importantly, this priming state can persist for several weeks (Aley et al., 2000; Ferrari et al., 2010; Parada et al., 2003a). Since G protein switch cannot be maintained long enough to sustain this primed state due to the intracellular protein turnover, it is more likely that these changes in intracellular signaling are the result of local protein translation adaptations. Translation can be quickly regulated by kinases cascades, particularly mechanistic target of rapamycin complex 1 (mTORC1) and extracellular signal regulated kinase (ERK), which have been shown to modulate IL6- and NGF-induced hyperalgesic priming (Melemedjian et al., 2010, 2014). Accordingly, their final effector, the Eukaryotic Initiation Factor 4F (eIF4F) complex (known to enhance translation), is also involved in hyperalgesic priming since blockade of its formation by 4EGI-1 prevents the hyperalgesic priming (Asiedu et al., 2011). In line with these results, mice lacking a phosphorylation site on eIF4E (part of the eIF4F complex) fail to develop hyperalgesic priming (Moy et al., 2017, 2018). Conversely, adenosine monophosphate-activated protein kinase (AMPK) that is able to decrease ERK, mTORC1and eIF4F formation in nociceptors (Melemedjian et al., 2011; Tillu et al., 2012) prevents establishment of priming when activated by resveratrol (Tillu et al., 2012). 
Another piece of evidence supporting translation modifications is the use of protein synthesis inhibitors. The co-administration of anisomycin with IL-6 prevents (but not reverse) the induction of hyperalgesic priming in mice (Asiedu et al., 2011) whereas in rats, rapamycin and cordycepin reverse it (Ferrari et al., 2013a). Thus, protein translation is mandatory for both development and maintenance of hyperalgesic priming. Further studies then demonstrated that cytoplasmic polyadenylation element binding protein (CPEB), a binding RNA protein that once phosphorylated induces an elongation of polyA to improve translation efficiency, is also a target of PKCE (Bogen et al., 2012). Accordingly, decrease in CPEB using antisense oligodeoxynucleotide prevents (but not reverse) hyperalgesic priming (Bogen et al., 2012). $\mathrm{Ca}^{2+} /$ calmodulin-activated protein kinase II $\alpha$ (CaMKII $\alpha$ ), that phosphorylates CPEB, was also shown to be involved because its activation induces priming and its inhibition prevents it (Ferrari et al., 2013b).

Although the name might imply it, hyperalgesic priming does not require an initial phase of hyperalgesia to be triggered. Indeed, exposure to unpredictable sound stress (Khasar et al., 2008) or repeated opioid administrations (Joseph et al., 2010) were also shown to elicit this primed state. Finally, this PKCE dependent priming shows sexual dimorphism in rats where in primed female $\mathrm{PGE}_{2}$ fails to precipitate hyperalgesia because of the presence of estrogen (Joseph et al., 2003).

More recently, a second type of hyperalgesic priming was described. This so called hyperalgesic priming type II is more rapidly induced than type I, is dependent on PKA (instead of PKCE), occurs in isolectin B4-negative nociceptors and develops in both male and female rats (Araldi et al., 2015, 2018b). While hyperalgesic priming type I is reversed by protein synthesis inhibitors, type II priming is reversed by co-administrations of Src and MAPK inhibitors (Araldi et al., 2017). 
Except for one study reporting hyperalgesic priming type II establishment following adenosine A1 receptor activation (Araldi et al., 2016a), this process was mostly evidenced in models of opioid-induced hyperalgesia. Repeated administrations of DAMGO at the primary fibers peripheral terminals produced an enhancement of $\mathrm{PGE}_{2}$-induced hyperalgesia (Araldi et al., 2015, 2017, 2018b) that was abolished, as expected, by isolectin B4-negative nociceptors depletion and by knocking down MOR using antisense oligodeoxynucleotides (Araldi et al., 2018b). $\mathrm{PGE}_{2}$ challenge also demonstrated that fentanyl, another MOR agonist, causes hyperalgesic priming type II (Araldi et al., 2018c; Khomula et al., 2021).

Intradermal, intrathecal or systemic acute fentanyl is able to elicit both types of priming: type I at the peripheral terminal and type II at the central terminal of nociceptors as assessed by reversion by protein translation inhibitors and Src and MAPK inhibitors, respectively (Araldi et al., 2018c; Khomula et al., 2021). The communication between central and peripheral terminals is mediated by intracellular $\mathrm{Ca}^{2+}$ since fentanyl-induced priming is prevented by administration of dantrolene (that blocks endoplasmic reticulum $\mathrm{Ca}^{2+}$ release) at either terminal. In accordance with these results, fentanyl induced intracellular $\mathrm{Ca}^{2+}$ increase in dorsal root ganglia is blocked by dantrolene. Using deletion of isolectin B4-positive (non peptidergic) and isolectin B4negative (peptidergic) nociceptors alone or in combination, the authors determined that intradermal fentanyl induces type II priming of peptidergic fibers and type I in peptidergic and non peptidergic nociceptors. As for intrathecally administered fentanyl, type II priming occurs in both types of nociceptors but type I in none of them, indicating that a third type of nociceptors might be involved (Araldi et al., 2018c). Similarly, hyperalgesic priming induced by systemic fentanyl is partially decreased by cordycepin (a protein translation inhibitor) or the combination of Src and mitogen activated protein kinase inhibitors. Those adaptations are held in weakly isolectin B4-positive and isolectin B4-negative nociceptors, since the increase in sensitizing effect of low doses of $\mathrm{PGE}_{2}$ (another key characteristic of priming) was observed in those 
neurons (Khomula et al., 2021). Finally, local or systemic administration of PZM21 and TRV130 (two MOR biased agonists) induces a marked prolonged $\mathrm{PGE}_{2}$ hyperalgesia that is reversed neither by protein translation inhibitors nor by Src and MAPK inhibitors, so that other mechanisms might be responsible for the maintenance of this priming (Araldi et al., 2018a). Altogether, those observations show that the division between type I (reversed by protein translation inhibitors and dependent on isolectin B4-positive nociceptors) and type II priming (reversed by Src and MAPK inhibitors and occurring in isolectin B4-negtive nociceptors) induced by opioids is not straightforward and seems to depend on MOR agonists and the administration mode used. However, hyperalgesic priming type II initiation requires MOR activation since knocking down this receptor with antisense oligodeoxynucleotides prevents it, a statement that seems consistent across those different models (Araldi et al., 2018b, 2018a, 2018c).

From a behavioral point of view, latent pain sensitization and hyperalgesic priming share some features. Both express as a long-lasting exacerbation in duration and/or magnitude of hyperalgesia in response to a subthreshold stimulus due to a primary insult or a stress. If latent pain sensitization comprises mainly mechanisms of central origin (pre- and post-synaptic neurons in the dorsal horn), hyperalgesic priming I is restricted to nociceptors peripheral endings and so far mechanisms underlying those models are quite different (Marvizón et al., 2015). However, hyperalgesic priming type II can also occur at primary fibers central terminals (Araldi et al., 2017), so that the relationship between this primed state and latent pain sensitization remains unclear. Levine and collaborators (Araldi et al., 2017) argue that latent pain sensitization is a form of hyperalgesic priming type II, since both are initiated by MOR activation (Araldi et al., 2018c; Célèrier et al., 2001) and reversed by the combination of Src and MAPK inhibitors (Araldi et al., 2017), so that they seem to involve similar intracellular signaling pathways. However, those observations were only made in CFA-sensitized animals and need to be 
extended to other models of latent pain sensitization. They also show that intradermal repeated DAMGO administrations, a model of hyperalgesic priming type II, also elicits latent pain sensitization as evidenced by naloxone-induced hyperalgesia (Araldi et al., 2017). Thus, those processes might partly overlap so that future studies should evaluate the presence of latent pain sensitization in models of hyperalgesic priming and vice versa to address this question. An interesting hypothesis is that these processes could represent successive steps toward pain chronification, where hyperalgesic priming (type I and perhaps type II) first sensitizes primary fibers and spreads to the spinal cord dorsal horn neurons (latent pain sensitization), to silently contribute and maintain the hyperalgesic state.

\section{Non neuronal mechanisms of latent pain sensitization}

It is now acknowledged that glia, in addition to neurons, contributes to pathophysiological mechanisms of chronic pain. Recent studies have also shown the role of glial cells in latent pain sensitization. It has been reported that both microglia and astrocytes are activated in the spinal cord and the dorsal root ganglia during the hyperalgesic phase, but only astrocytes can be reactivated by naloxone administration (Romero et al., 2013). Thus, activated microglia contribute to early stages of latent pain sensitization development and activated astrocytes contribute to its maintenance. In agreement with these results, preventive (but not curative) blockade of microglial activation blocks latent pain sensitization while simultaneous blockade of both microglia and astrocytes reverses it in a model of non-specific low back pain (Zhang et al., 2017). Another study suggests that the preventive effects of ketamine and gabapentin treatment in latent pain sensitization could be partially mediated through activation of astrocytes following postoperative pain (Romero-Alejo et al., 2016b). In the same model, tramadol partially prevents naloxone induced-hyperalgesia without preventing astrocyte re-activation (Romero-Alejo et al., 2016a), suggesting that blockade of latent pain sensitization does not involve activated astrocytes. Consequently, their participation does not seem mandatory for latent pain 
sensitization maintenance. Interestingly, astrocytes are reactivated by both (-) naloxone (binds to neuronal opioid receptors and Toll Like Receptor 4 (TLR4)) and (+) naloxone (binds to TLR4 only), indicating that activated astrocytes contribution to latent pain sensitization is mediated indirectly by TLR4 (Romero et al., 2013). More investigations are needed to characterize the molecular mechanisms driving astrocytes activation and how they interact with neurons.

\section{Other relevant factors in the establishment of latent pain}

\section{sensitization}

\subsection{Genetic factors}

\subsubsection{Strain and species}

As mentioned before, long-term pain vulnerability is a common phenomenon found in mouse, rats and possibly humans (Pereira et al., 2015a). If it was evidenced in different mouse strains including Swiss CD1 (Cabañero et al., 2009) and C57B16 mice (Corder et al., 2013), rats' studies were only performed with Sprague-Dawley rats. Indeed, a study compared latent pain sensitization development in various strains of rats and reported that Fischer rats do not show long-term pain hypersensitivity since they do not develop opioid-induced hyperalgesia (Laboureyras et al., 2014). Although establishment of latent pain sensitization in Fisher rats was not investigated in chronic pain models, these data most likely reflect variability in behavioral signs of pain between strains that are already known in acute pain (Larivière et al., 2001). Consequently, latent pain sensitization could be a useful model that recapitulates both genetic background and individual histories that might contribute to the disparity in developing chronic pain in humans.

\subsubsection{Sex}

Most of the studies mentioned above were performed on male rodents but latent pain sensitization has also been demonstrated in females (Corder et al., 2013; Custodio-Patsey et al., 
2020; Severino et al., 2018). From a behavioral point of view, latent pain sensitization occurs similarly in both sexes, but mechanisms underlying this process are slightly different. In males, tonic inhibition of pain is sustained by MOR localized in primary afferents whereas in females spinal or supraspinal MOR might contribute too, as attested by the weak naltrexone induced hyperalgesia in female mice depleted for MOR in primary nociceptors (Severino et al., 2018). Besides, blockade of KOR with LY2456302 slightly enhanced the hyperalgesic state and the number of $\mathrm{pERK}+$ neurons in the dorsal horn of females compared to males (Custodio-Patsey et al., 2020), pointing out a more pronounced KOR-sustained suppression of hyperalgesia in females. Sex is then an important factor in the neuroadaptive processes leading to latent pain sensitization, at least concerning opioid receptors. Consequently, the question of sex differences for the other anti-nociceptive receptors (such as DOR, $\alpha_{2 \mathrm{~A}}$, NPY and CRF receptor) arises and further studies should be performed on both sexes to systematically assess those differences.

\subsection{Environmental factors}

Chronic pain disorders are sensitive to external factors. Notably, stressful events play a role in the pathophysiology of pain. Similarly, stress seems to enhance long-lasting pain vulnerability. In fentanyl-carrageenan treated rats, the length of the hyperalgesic phase increases with the number of stress sessions (Le Roy et al., 2011). Thus, latent pain sensitization could be considered as a model of chronic pain that integrates prior life events. Importantly, this process is also impacted by diet, as polyamine deficient food (aiming to negatively modulate NMDA receptors) can oppose to the development of latent pain sensitization in carrageenan/fentanyl and incision/fentanyl rats (Rivat et al., 2008).

\section{Conclusion}

Pain resolution is not a mere return to the basal state but is associated with the progressive and compensatory activation of opioid, $\alpha_{2 \mathrm{~A}}$, NPY, CRF and cannabinoid receptors. They exert a 
sustained repression of the hyperalgesia mediated by the NMDA-AC1 pathway, AMPA and NK1 receptors. Pain silently persists but is restricted within a state of apparent remission. Those adaptations, first aiming to protect from acute pain, paradoxically lead to a long-term vulnerability to "relapse" following anti-nociceptive systems disruption.

Interestingly, pain episodes can also be triggered by acute stress, similarly to some types of chronic pain disorders in humans. Latent pain sensitization is then both a model and a hypothesis for pain chronification. However, preclinical studies mostly evaluated nociceptive aspects of pain, which cannot depict the complexity of the pain experience in humans. Accordingly, latent pain sensitization was mostly evidenced in rodents' models of chronic pain, but still need to be established in chronic pain patients. In this case, further studies will be needed to determine more precisely its underlying molecular mechanisms. This would provide new insights on therapeutic strategies design by identifying new targets. Notably, further chronic pain treatment developed should display not only analgesic but also anti-hyperalgesic properties that could prevent the transition from acute to chronic pain such as ZH853 (Feehan and Zadina, 2019) or nefopam (Laboureyras et al., 2009). 


\section{Conflict of Interest Statement}

The authors declare that there are no conflicts of interest.

\section{Acknowledgements}

This work was supported by the CNRS and Université de Strasbourg. It has been published within the LABEX Medalis/Institut du Médicament de Strasbourg and received financial support from the French government managed by "Agence National de la Recherche" under "Programme d'investissement d'avenir" (ANR-10-LABX-0034 and ANR-17-EURE-0022, EURIDOL graduate school of pain).

The present manuscript has not been published previously and is not under consideration for publication elsewhere. 


\section{Figure legends}

Figure 1. Pro-nociceptive and anti-nociceptive systems balance hypothesis. A. At the basal state, called homeostasia, anti- and pro-nociceptive systems are balanced and poorly activated. B. Inflammation, nerve injury or repeated administrations of opioids stimulate pro-nociceptive systems that promotes hypersensitivity to pain or hyperalgesia. C. Endogenous anti-nociceptive systems (including opioid system) activate to compensate pro-nociceptive systems activity, which results in a progressive return to basal nociceptive threshold until complete hyperalgesia resolution. Both anti-nociceptive and pro-nociceptive systems are now highly actived but at the equilibrium, this state is referred as latent pain sensitization. D. Once this new equilibrium is disrupted by a stress or with antagonists of antinociceptive systems a new episode of hyperalgesia ensues due to the high activity of pro-nociceptive systems. This highlights the abnormal and sustained activation of pronociceptive systems underlying latent pain sensitization. Adapted from Célérier et al., 2001.

Figure 2. Receptors and signaling pathways involved in latent pain sensitization. In nociceptor central terminals (middle panel), Adenylate Cyclase type 1 (AC1) can be activated by NMDA receptors or repressed by G-protein coupled receptors. Mu Opioid Receptor (MOR) activation by endogenous opioids (or Y1 receptor activation by NPY) decreases substance P (or neurotransmitter) release via an inhibition of AC1-cAMP-Protein Kinase A (PKA) signaling pathway. Thus, the nociceptive signal is attenuated. In post-synaptic neurons (lower panel), AC1 is also a key element of latent pain sensitization. Y1 receptor and MOR (ligand-dependent or independent manner) activation dampen neuronal excitability via a decrease in cAMP. Elements downstream cAMP and the origin of NPY in the synaptic cleft remain to be determined. Both pre-synaptic and post-synaptic actions lead to a decrease in nociceptive signal transmission, then contribute to mask the hyperalgesic state and make it "latent" (latent pain sensitization). 
Abbreviations : AC1 : Adenylate Cyclase type 1 ; AMPA : $\alpha$-Amino-3-hydroxy-5-methyl-4isoxazolepropionic acid ; AMPA-R : $\alpha$-Amino-3-hydroxy-5-methyl-4-isoxazolepropionic acid Receptor ; ATP : Adenosine Triphosphate ; cAMP : cyclic adenosine monophosphate ; Epac : Exchange Protein directly Activated by cAMP ; MOR : Mu Opioid Receptor NGF : Nerve Growth Factor ; NMDA : N-Methyl-D-aspartate ; NMDA-R : N-Methyl-D-aspartate Receptor ; NPY : Neuropeptide Y ; TRPA1 : Transient Receptor Potential Ankyrin 1; TRPV1 : Transient Receptor Potential Vanilloid type 1; Y1R : NPY receptor type 1. Created with BioRender. 


\section{References}

Abe, T., Matsumura, S., Katano, T., Mabuchi, T., Takagi, K., Xu, L., Yamamoto, A., Hattori, K., Yagi, T., Watanabe, M., Nakazawa, T., Yamamoto, T., Mishina, M., Nakai, Y., \& Ito, S. (2005). Fyn kinase-mediated phosphorylation of NMDA receptor NR2B subunit at Tyr1472 is essential for maintenance of neuropathic pain. European Journal of Neuroscience, 22, 1445-1454.

Alexander, J. K., DeVries, A. C., Kigerl, K. A., Dahlman, J. M., \& Popovich, P. G. (2009). Stress exacerbates neuropathic pain via glucocorticoid and NMDA receptor activation. Brain, Behavior, and Immunity, 23, 851-860.

Aley, K. O., \& Levine, J. D. (1999). Role of protein kinase A in the maintenance of inflammatory pain. Journal of Neuroscience, 19, 2181-2186.

Aley, K. O., Messing, R. O., Mochly-Rosen, D., \& Levine, J. D. (2000). Chronic hypersensitivity for inflammatory nociceptor sensitization mediated by the $\varepsilon$ isozyme of protein kinase C. Journal of Neuroscience, 20, 4680-4685.

Angst, M. S., \& Clark, J. D. (2006). Opioid-induced hyperalgesia: A qualitative systematic review. Acute Pain, 104, 570-587.

Appel, C. K., Gallego-Pedersen, S., Andersen, L., Blancheflor Kristensen, S., Ding, M., Falk, S., Sayilekshmy, M., Gabel-Jensen, C., \& Heegaard, A. M. (2017). The Src family kinase inhibitor dasatinib delays pain-related behaviour and conserves bone in a rat model of cancer-induced bone pain. Scientific Reports, 7, 1-14.

Araldi, D., Ferrari, L. F., \& Levine, J. D. (2015). Repeated mu-opioid exposure induces a novel form of the hyperalgesic priming model for transition to chronic pain. Journal of Neuroscience, $35,12502-12517$. 
Araldi, D., Ferrari, L. F., \& Levine, J. D. (2016a). Adenosine-A1 receptor agonist induced hyperalgesic priming type II. Pain, 157, 698-709.

Araldi, D., Ferrari, L. F., \& Levine, J. D. (2016b). Gi-Protein Coupled 5-HT1B/D Receptor Agonist Sumatriptan Induces Type I Hyperalgesic Priming. Pain, 157, 1773-1782.

Araldi, D., Ferrari, L. F., \& Levine, J. D. (2017). Hyperalgesic priming (type II) induced by repeated opioid exposure: Maintenance mechanisms. Pain, 158, 1204-1216.

Araldi, D., Ferrari, L. F., \& Levine, J. D. (2018a). Mu-Opioid Receptor (MOR) Biased Agonists Induce Biphasic Dose-dependent Hyperalgesia and Analgesia, and Hyperalgesic Priming in the Rat. Neuroscience, 394, 60-71.

Araldi, D., Ferrari, L. F., \& Levine, J. D. (2018b). Role of GPCR (mu-opioid)-receptor tyrosine kinase (epidermal growth factor) crosstalk in opioid-induced hyperalgesic priming (type II). Pain, 159, 864-875.

Araldi, D., Khomula, E. V., Ferrari, L. F., \& Levine, J. D. (2018c). Fentanyl induces rapid onset hyperalgesic priming: Type I at peripheral and type II at central nociceptor terminals. Journal of Neuroscience, 38, 2226-2245.

Asiedu, M. N., Tillu, D. V., Melemedjian, O. K., Shy, A., Sanoja, R., Bodell, B., Ghosh, S., Porreca, F., \& Price, T. J. (2011). Spinal protein kinase M $£$ underlies the maintenance mechanism of persistent nociceptive sensitization. Journal of Neuroscience, 31, 6646-6653.

Attal, N. (2019). Pharmacological treatments of neuropathic pain: The latest recommendations. Revue Neurologique, 175, 46-50.

Baron, E. P. (2015). Comprehensive review of medicinal marijuana, cannabinoids, and therapeutic implications in medicine and headache: What a long strange trip it's been ... Headache, 55, 885-916. 
Besse, D., Lombard, M. C., Zajac, J. M., Roques, B. P., \& Besson, J. M. (1990). Pre- and postsynaptic distribution of $\mu, \delta$ and $\kappa$ opioid receptors in the superficial layers of the cervical dorsal horn of the rat spinal cord. Brain Research, 521, 15-22.

Bessière, B., Laboureyras, E., Laulin, J. P., \& Simonnet, G. (2010). Xenon prevents inflammation-induced delayed pain hypersensitivity in rats. NeuroReport, 21, 1167-1171.

Bessière, B., Richebé, P., Laboureyras, E., Laulin, J. P., Contarino, A., \& Simonnet, G. (2007). Nitrous oxide (N2O) prevents latent pain sensitization and long-term anxiety-like behavior in pain and opioid-experienced rats. Neuropharmacology, 53, 733-740.

Bigal, M. E., \& Lipton, R. B. (2008). Clinical course in migraine: Conceptualizing migraine transformation. Neurology, 71, 848-855.

Blanchard, E. B., Lackner, J. M., Jaccard, J., Rowell, D., Carosella, A. M., Powell, C., Sanders, K., Krasner, S., \& Kuhn, E. (2008). The role of stress in symptom exacerbation among IBS patients. Journal of Psychosomatic Research, 64, 119-128.

Bogen, O., Alessandri-Haber, N., Chu, C., Gear, R. W., \& Levine, J. D. (2012). Generation of a pain memory in the primary afferent nociceptor triggered by $\mathrm{PKC} \varepsilon$ activation of CPEB. Journal of Neuroscience, 32, 2018-2026.

Bonnica, J. (1953). The management of pain. Philadelphia: Lea \& Febiger.

Brumovsky, P., Stanic, D., Shuster, S., Herzog, H., Villar, M., \& Hökfelt, T. (2005). Neuropeptide Y2 receptor protein is present in peptidergic and nonpeptidergic primary sensory neurons of the mouse. Journal of Comparative Neurology, 489, 328-348.

Busserolles, J., Lolignier, S., Kerckhove, N., Bertin, C., Authier, N., \& Eschalier, A. (2020). Replacement of current opioid drugs focusing on MOR-related strategies. Pharmacology and Therapeutics, 210, 107519. 
Cabañero, D., Baker, A., Zhou, S., Hargett, G. L., Irie, T., Xia, Y., Beaudry, H., Gendron, L., Melyan, Z., Carlton, S. M., \& Morón, J. A. (2013). Pain after discontinuation of morphine treatment is associated with synaptic increase of GluA4-containing AMPAR in the dorsal horn of the spinal cord. Neuropsychopharmacology, 38, 1472-1484.

Cabañero, D., Campillo, A., Célérier, E., Romero, A., \& Puig, M. M. (2009). Pronociceptive effects of remifentanil in a mouse model of postsurgical pain: Effect of a second surgery. Anesthesiology, 111, 1334-1345.

Campillo, A., Cabañero, D., Romero, A., García-Nogales, P., \& Puig, M. M. (2011). Delayed postoperative latent pain sensitization revealed by the systemic administration of opioid antagonists in mice. European Journal of Pharmacology, 657, 89-96.

Cassidy, J. D., Côté, P., Carroll, L. J., \& Kristman, V. (2005). Incidence and Course of Low Back Pain Episodes in the General Population. Spine, 30, 2817-2823.

Célèrier, E., Laulin, J. P., Corcuff, J. B., Le Moal, M., \& Simonnet, G. (2001). Progressive enhancement of delayed hyperalgesia induced by repeated heroin administration: A sensitization process. Journal of Neuroscience, 21, 4074-4080.

Célèrier, E., Laulin, J. P., Larcher, A., Le Moal, M., \& Simonnet, G. (1999). Evidence for opiateactivated NMDA processes masking opiate analgesia in rats. Brain Research, 847, 18-25.

Célèrier, E., Rivat, C., Jun, Y., Laulin, J. P., Larcher, A., Reynier, P., \& Simonnet, G. (2000). Long-lasting hyperalgesia induced by fentanyl in rats: Preventive effect of ketamine. Anesthesiology, 92, 465-472.

Chen, S. R., Zhou, H. Y., Byun, H. S., \& Pan, H. L. (2013). Nerve injury increases GluA2lacking AMPA receptor prevalence in spinal cords: Functional significance and signaling mechanisms. Journal of Pharmacology and Experimental Therapeutics, 347, 765-772. 
Chen, W., Ennes, H. S., McRoberts, J. A., \& Marvizón, J. C. (2018a). Mechanisms of $\mu$-opioid receptor inhibition of NMDA receptor-induced substance $\mathrm{P}$ release in the rat spinal cord. Neuropharmacology, 128, 255-268.

Chen, W., \& Marvizón, J. C. (2020a). A Src family kinase maintains latent sensitization in rats, a model of inflammatory and neuropathic pain. Brain Research, 1746, 146999.

Chen, W., \& Marvizón, J. C. (2020b). Neurokinin 1 receptor activation in the rat spinal cord maintains latent sensitization, a model of inflammatory and neuropathic chronic pain. Neuropharmacology, 177, 108253.

Chen, W., Taché, Y., \& Marvizón, J. C. (2018b). Corticotropin-Releasing Factor in the Brain and Blocking Spinal Descending Signals Induce Hyperalgesia in the Latent Sensitization Model of Chronic Pain. Neuroscience, 381, 149-158.

Chen, W., Zhang, G., \& Marvizón, J. C. (2010). NMDA receptors in primary afferents require phosphorylation by Src family kinases to induce substance $\mathrm{P}$ release in the rat spinal cord. Neuroscience, 166, 924-934.

Chou, R., Turner, J. A., Devine, E. B., Hansen, R. N., Sullivan, S. D., Blazina, I., Dana, T., Bougatsos, C., \& Deyo, R. A. (2015). The Effectiveness and Risks of Long-Term Opioid Therapy for Chronic Pain: A Systematic Review for a National Institutes of Health Pathways to Prevention Workshop. Annals of Internal Medicine, 162, 276-286.

Corder, G., Doolen, S., Donahue, R. R., Winter, M. K., Jutras, B. L., He, Y., Hu, X., Wieskopf, J. S., Mogil, J. S., Storm, D. R., Wang, Z. J., McCarson, K. E., \& Taylor, B. K. (2013). Constitutive $\mu$-opioid receptor activity leads to long-term endogenous analgesia and dependence. Science, 341, 1394-1399. 
Custodio-Patsey, L., Donahue, R. R., Fu, W., Lambert, J., Smith, B. N., \& Taylor, B. K. (2020). Sex differences in kappa opioid receptor inhibition of latent postoperative pain sensitization in dorsal horn. Neuropharmacology, 163, 107726.

Dina, O. A., Green, P. G., \& Levine, J. D. (2008). Role of interleukin-6 in chronic muscle hyperalgesic priming. Neuroscience, 152, 521-525.

Dina, O. A., Khasar, S. G., Gear, R. W., \& Levine, J. D. (2009). Activation of Gi induces mechanical hyperalgesia poststress or inflammation. Neuroscience, 160, 501-507.

Emery, P. C., Wilson, K. G., \& Kowal, J. (2014). Major depressive disorder and sleep disturbance in patients with chronic pain. Pain Research and Management, 19, 35-41.

Eriksen, J., Sjøgren, P., Bruera, E., Ekholm, O., \& Rasmussen, N. K. (2006). Critical issues on opioids in chronic non-cancer pain:. An epidemiological study. Pain, 125, 172-179.

Feehan, A. K., \& Zadina, J. E. (2019). Morphine immunomodulation prolongs inflammatory and postoperative pain while the novel analgesic ZH853 accelerates recovery and protects against latent sensitization. Journal of Neuroinflammation, 16, 1-20.

Ferrari, L. F., Araldi, D., Bogen, O., Green, P. G., \& Levine, J. D. (2019). Systemic Morphine Produces Dose-dependent Nociceptor-mediated Biphasic Changes in Nociceptive Threshold and Neuroplasticity. Neuroscience, 398, 64-75.

Ferrari, L. F., Bogen, O., Chu, C., \& Levine, J. D. (2013a). Peripheral administration of translation inhibitors reverses increased hyperalgesia in a model of chronic pain in the rat. Journal of Pain, 14, 731-738.

Ferrari, L. F., Bogen, O., \& Levine, J. D. (2010). Nociceptor Subpopulations Involved in Hyperalgesic Priming. Neuroscience, 165, 896-901. 
Ferrari, L. F., Bogen, O., \& Levine, J. D. (2013b). Role of nociceptor $\alpha$ CaMKII in transition from acute to chronic pain (hyperalgesic priming) in male and female rats. Journal of Neuroscience, 33, 11002-11011.

Fu, W., Nelson, T. S., Santos, D. F., Doolen, S., Gutierrez, J. J. P., Ye, N., Zhou, J., \& K Taylor, B. (2019). An NPY Y1 receptor antagonist unmasks latent sensitization and reveals the contribution of protein kinase A and Epac to chronic inflammatory pain. Pain, 160, 1754-1765.

Fu, W., Wessel, C. R., \& Taylor, B. K. (2020). Neuropeptide Y tonically inhibits an NMDAR AC1 TRPA1/TRPV1 mechanism of the affective dimension of chronic neuropathic pain. Neuropeptides, 80, 102024.

Fu, Y., \& Neugebauer, V. (2008). Differential mechanisms of CRF1 and CRF2 receptor functions in the amygdala in pain-related synaptic facilitation and behavior. Journal of Neuroscience, 28, 3861-3876.

Gibson, S. J., Polak, J. M., Allen, J. M., Adrian, T. E., Kelly, J. S., \& Bloom, S. R. (1984). The distribution and origin of a novel brain peptide, neuropeptide $\mathrm{Y}$, in the spinal cord of several mammals. Journal of Comparative Neurology, 227, 78-91.

Guan, Y., Yuan, F., Carteret, A. F., \& Raja, S. N. (2010). A partial L5 spinal nerve ligation induces a limited prolongation of mechanical allodynia in rats: An efficient model for studying mechanisms of neuropathic pain. Neuroscience Letters, 471, 43-47.

Guo, W., Zou, S., Guan, Y., Ikeda, T., Tal, M., Dubner, R., \& Ren, K. (2002). Tyrosine phosphorylation of the NR2B subunit of the NMDA receptor in the spinal cord during the development and maintenance of inflammatory hyperalgesia. Journal of Neuroscience, 22, 62086217. 
Hildebrand, M. E., Xu, J., Dedek, A., Li, Y., Sengar, A. S., Beggs, S., Lombroso, P. J., \& Salter, M. W. (2016). Potentiation of Synaptic GluN2B NMDAR Currents by Fyn Kinase Is Gated through BDNF-Mediated Disinhibition in Spinal Pain Processing. Cell Reports, 17, 2753-2765.

Hucho, T. B., Dina, O. A., \& Levine, J. D. (2005). Epac mediates a cAMP-to-PKC signaling in inflammatory pain: An isolectin B4(+) neuron-specific mechanism. Journal of Neuroscience, 25, 6119-6126.

Intondi, A. B., Dahlgren, M. N., Eilers, M. A., \& Taylor, B. K. (2008). Intrathecal neuropeptide $\mathrm{Y}$ reduces behavioral and molecular markers of inflammatory or neuropathic pain. Pain, 137, 352-365.

Intondi, A. B., Zadina, J. E., Zhang, X., \& Taylor, B. K. (2010). Topography and time course of changes in spinal neuropeptide Y immunoreactivity after spared nerve injury. Neuroscience, 165, 914-922.

Jackson, T., Thomas, S., Stabile, V., Shotwell, M., Han, X., \& McQueen, K. (2016). A Systematic Review and Meta-Analysis of the Global Burden of Chronic Pain Without Clear Etiology in Low- and Middle-Income Countries: Trends in Heterogeneous Data and a Proposal for New Assessment Methods. Anesthesia and Analgesia, 123, 739-748.

Ji, G., \& Neugebauer, V. (2008). Pro- and anti-nociceptive effects of Corticotropin-Releasing Factor (CRF) in central amygdala neurons are mediated through different receptors. Journal of Neurophysiology, 99, 1201-1212.

Joseph, E. K., Bogen, O., Alessandri-Haber, N., \& Levine, J. D. (2007). PLC- $\beta 3$ signals upstream of PKC $\varepsilon$ in acute and chronic inflammatory hyperalgesia. Pain, 132, 67-73.

Joseph, E. K., \& Levine, J. D. (2010). Hyperalgesic priming is restricted to isolectin B4-positive nociceptors. Neuroscience, $169,431-435$. 
Joseph, E. K., Parada, C. A., \& Levine, J. D. (2003). Hyperalgesic priming in the rat demonstrates marked sexual dimorphism. Pain, 105, 143-150.

Joseph, E. K., Reichling, D. B., \& Levine, J. D. (2010). Shared mechanisms for opioid tolerance and a transition to chronic pain. Journal of Neuroscience, 30, 4660-4666.

Kandasamy, R., \& Price, T. J. (2015). The pharmacology of nociceptor priming. Handbook of Experimental Pharmacology, 227, 15-37.

Khasar, S. G., Burkham, J., Dina, O. A., Brown, A. S., Bogen, O., Alessandri-Haber, N., Green, P. G., Reichling, D. B., \& Levine, J. D. (2008). Stress induces a switch of intracellular signaling in sensory neurons in a model of generalized pain. Journal of Neuroscience, 28, 5721-5730.

Khomula, E. V., Araldi, D., Bonet, I. J., \& Levine, J. D. (2021). Opioid-Induced Hyperalgesic Priming in Single Nociceptors. The Journal of Neuroscience, 41, 31-46.

Kim, D. H., Fields, H. L., \& Barbaro, N. M. (1990). Morphine analgesia and acute physical dependence : Rapid onset of two opposing, dose-related processes. Brain Research, 516, 37-40.

Kohno, T., Kumamoto, E., Higashi, H., Shimoji, K., \& Yoshimura, M. (1999). Actions of opioids on excitatory and inhibitory transmission in substantia gelatinosa of adult rat spinal cord. Journal of Physiology, 518, 803-813.

Kopp, J., Xu, Z. Q., Zhang, X., Pedrazzini, T., Herzog, H., Kresse, A., Wong, H., Walsh, J. H., \& Hökfelt, T. (2002). Expression of the neuropeptide Y Y1 receptor in the CNS of rat and of wild-type and Y1 receptor knock-out mice. Focus on immunohistochemical localization. Neuroscience, 111, 443-532.

Kopruszinski, C. M., Navratilova, E., Vagnerova, B., Swiokla, J., Patwardhan, A., Dodick, D., \& Porreca, F. (2020). Cannabinoids induce latent sensitization in a preclinical model of medication overuse headache. Cephalalgia, 40, 68-78. 
Laboureyras, E., Aubrun, F., Monsaingeon, M., Corcuff, J. B., Laulin, J. P., \& Simonnet, G. (2014). Exogenous and endogenous opioid-induced pain hypersensitivity in different rat strains. Pain Research and Management, 19, 191-197.

Laboureyras, E., Chateauraynaud, J., Richebé, P., \& Simonnet, G. (2009). Long-term pain vulnerability after surgery in rats: Prevention by nefopam, an analgesic with antihyperalgesic properties. Anesthesia and Analgesia, 109, 623-631.

Lai, C. Y., Lin, T. B., Hsieh, M. C., Chen, G. D., \& Peng, H. Y. (2016). SIRPa1-SHP2 Interaction Regulates Complete Freund Adjuvant-Induced Inflammatory Pain via Src-Dependent GluN2B Phosphorylation in Rats. Anesthesia and Analgesia, 122, 871-881.

Larcher, A., Laulin, J. P., Celerier, E., Le Moal, M., \& Simonnet, G. (1998). Acute tolerance associated with a single opiate administration: Involvement of N-methyl-D-aspartate-dependent pain facilitatory systems. Neuroscience, $84,583-589$.

Larivière, W. R., Chesler, E. J., \& Mogil, J. S. (2001). Transgenic Studies of Pain and Analgesia : Mutation or Background Genotype? The Journal of pharmacology and experimental therapeutics, 297, 467-473.

Latremoliere, A., \& Woolf, C. J. (2009). Central Sensitization: A Generator of Pain Hypersensitivity by Central Neural Plasticity. Journal of Pain, 10, 895-926.

Laulin, J. P., Larcher, A., Célèrier, E., Le Moal, M., \& Simonnet, G. (1998). Long-lasting increased pain sensitivity in rat following exposure to heroin for the first time. European Journal of Neuroscience, 10, 782-785.

Laulin, J. P., Maurette, P., Corcuff, J. B., Rivat, C., Chauvin, M., \& Simonnet, G. (2002). The role of ketamine in preventing fentanyl-induced hyperalgesia and subsequent acute morphine tolerance. Anesthesia and Analgesia, 94, 1263-1269. 
Le Roy, C., Laboureyras, E., Gavello-Baudy, S., Chateauraynaud, J., Laulin, J. P., \& Simonnet, G. (2011). Endogenous opioids released during non-nociceptive environmental stress induce latent pain sensitization via a NMDA-dependent process. Journal of Pain, 12, 1069-1079.

Lian, B., Vera-Portocarrero, L., King, T., Ossipov, M. H., \& Porreca, F. (2010). Opioid-induced latent sensitization in a model of non-inflammatory viscerosomatic hypersensitivity. Brain Research, 1358, 64-70.

Loeser, J. D., \& Treede, R. D. (2008). The Kyoto protocol of IASP Basic Pain Terminology. Pain, 137, 473-477.

Mansour, A., Fox, C. A., Akil, H., \& Watson, S. J. (1995). Opioid-receptor mRNA expression in the rat CNS: anatomical and functional implications. Trends in Neurosciences, 18, 22-29.

Marmura, M. J. (2018). Triggers, Protectors, and Predictors in Episodic Migraine. Current Pain and Headache Reports, 22, 81.

Marvizón, J. C., Martínez, V., Grady, E. F., Bunnett, N. W., \& Mayer, E. A. (1997). Neurokinin 1 receptor internalization in spinal cord slices induced by dorsal root stimulation is mediated by NMDA receptors. Journal of Neuroscience, 17, 8129-8136.

Marvizón, J. C., Walwyn, W., Minasyan, A., Chen, W., \& Taylor, B. K. (2015). Latent sensitization: A model for stress-sensitive chronic pain. Current Protocols in Neuroscience, 71, $9.50 .1-9.50 .15$

Mattson, C. L., Tanz, L. J., Quinn, K., Mbabazi, K., Patel, P., \& Davis, N. L. (2021). Trends and Geographic Patterns in Drug and Synthetic Opioid Overdose Deaths-United States, 2013-2019. MMWR. Morbidity and Mortality Weekly Report, 70, 202-206. 
McNally, G. P. (1999). Pain facilitatory circuits in the mammalian central nervous system : Their behavioral significance and role in morphine analgesic tolerance. Neuroscience and Biobehavioral Reviews, 23, 1059-1078.

Melemedjian, O. K., Asiedu, M. N., Tillu, D. V., Peebles, K. A., Yan, J., Ertz, N., Dussor, G. O., \& Price, T. J. (2010). IL-6- and NGF-induced rapid control of protein synthesis and nociceptive plasticity via convergent signaling to the eIF4F complex. Journal of Neuroscience, 30, 1511315123.

Melemedjian, O. K., Asiedu, M. N., Tillu, D. V., Sanoja, R., Yan, J., Lark, A., Khoutorsky, A., Johnson, J., Peebles, K. A., Lepow, T., Sonenberg, N., Dussor, G., \& Price, T. J. (2011). Targeting adenosine monophosphate-activated protein kinase (AMPK) in preclinical models reveals a potential mechanism for the treatment of neuropathic pain. Molecular Pain, 7, 70 .

Melemedjian, O. K., Tillu, D. V., Moy, J. K., Asiedu, M. N., Mandell, E. K., Ghosh, S., Dussor, G., \& Price, T. J. (2014). Local translation and retrograde axonal transport of CREB regulates IL-6-induced nociceptive plasticity. Molecular Pain, 10, 45.

Mercadante, S., Radbruch, L., Caraceni, A., Cherny, N., Kaasa, S., Nauck, F., Ripamonti, C., De Conno, F., \& Steering Committee of the European Association for Palliative Care (EAPC) Research Network. (2002). Episodic (breakthrough) pain: Consensus conference of an expert working group of the European Association for Palliative Care. Cancer, 94, 832-839.

Meye, F. J., van Zessen, R., Smidt, M. P., Adan, R. A. H., \& Ramakers, G. M. (2012). Morphine withdrawal enhances constitutive $\mu$-opioid receptor activity in the ventral tegmental area. Journal of Neuroscience, 32, 16120-16128.

Moy, J. K., Khoutorsky, A., Asiedu, M. N., Black, B. J., Kuhn, J. L., Barragán-Iglesias, P., Megat, S., Burton, M. D., Burgos-Vega, C. C., Melemedjian, O. K., Boitano, S., Vagner, J., Gkogkas, C. G., Pancrazio, J. J., Mogil, J. S., Dussor, G., Sonenberg, N., \& Price, T. J. (2017). 
The MNK-eIF4E signaling axis contributes to injury-induced nociceptive plasticity and the development of chronic pain. Journal of Neuroscience, 37, 7481-7499.

Moy, J. K., Kuhn, J. L., Szabo-Pardi, T. A., Pradhan, G., \& Price, T. J. (2018). EIF4E phosphorylation regulates ongoing pain, independently of inflammation, and hyperalgesic priming in the mouse CFA model. Neurobiology of Pain, 4, 45-50.

Nolet, P. S., Cote, P., Cassidy, J. D., \& Carroll, L. J. (2010). The association between a lifetime history of a neck injury in a motor vehicle collision and future neck pain: A population-based cohort study. Eur Spine J, 10.

Palsson, O. S., Baggish, J., \& Whitehead, W. E. (2014). Episodic Nature of Symptoms in Irritable Bowel Syndrome. American Journal of Gastroenterology, 109, 1450-1460.

Parada, C. A., Reichling, D. B., \& Levine, J. D. (2005). Chronic hyperalgesic priming in the rat involves a novel interaction between cAMP and PKC $\varepsilon$ second messenger pathways. Pain, 113, 185-190.

Parada, C. A., Yeh, J. J., Joseph, E. K., \& Levine, J. D. (2003a). Tumor necrosis factor receptor type-1 in sensory neurons contributes to induction of chronic enhancement of inflammatory hyperalgesia in rat. European Journal of Neuroscience, 17, 1847-1852.

Parada, C. A., Yeh, J. J., Reichling, D. B., \& Levine, J. D. (2003b). Transient attenuation of protein kinase $\mathrm{C} \varepsilon$ can terminate a chronic hyperalgesic state in the rat. Neuroscience, 120, 219226.

Pereira, M. P., Donahue, R. R., Dahl, J. B., Werner, M., Taylor, B. K., \& Werner, M. U. (2015a). Endogenous opioid-masked latent pain sensitization: Studies from mouse to human. PLoS one, $10, \mathrm{e} 0134441$. 
Pereira, M. P., Werner, M. U., \& Dahl, J. B. (2015b). Effect of a high-dose target-controlled naloxone infusion on pain and hyperalgesia in patients following groin hernia repair: Study protocol for a randomized controlled trial. Trials, 16, 511.

Pereira, M. P., Werner, M. U., Ringsted, T. K., Rowbotham, M. C., Taylor, B. K., \& Dahl, J. B. (2013). Does Naloxone Reinstate Secondary Hyperalgesia in Humans after Resolution of a Burn Injury? A Placebo-Controlled, Double-Blind, Randomized, Cross-Over Study. PLoS ONE, 8, e64608.

Pertovaara, A. (2006). Noradrenergic pain modulation. Progress in Neurobiology, 80, 53-83.

Reichling, D. B., \& Levine, J. D. (2009). Critical role of nociceptor plasticity in chronic pain. Trends in Neurosciences, 32, 611-618.

Richebé, P., Rivat, C., Laulin, J. P., Maurette, P., \& Simonnet, G. (2005). Ketamine improves the management of exaggerated postoperative pain observed in perioperative fentanyl-treated rats. Anesthesiology, 102, 421-428.

Rivat, C., Laboureyras, E., Laulin, J. P., Le Roy, C., Richebé, P., \& Simonnet, G. (2007). NonNociceptive Environmental Stress Induces Hyperalgesia, Not Analgesia, in Pain and OpioidExperienced Rats. Neuropsychopharmacology, 32, 2217-2228.

Rivat, C., Laulin, J. P., Corcuff, J. B., Célèrier, E., Pain, L., \& Simonnet, G. (2002). Fentanyl enhancement of carrageenan-induced long-lasting hyperalgesia in rats: Prevention by the Nmethyl-D-aspartate receptor antagonist ketamine. Anesthesiology, 96, 381-391.

Rivat, C., Richebé, P., Laboureyras, E., Laulin, J. P., Havouis, R., Noble, F., Moulinoux, J. P., \& Simonnet, G. (2008). Polyamine deficient diet to relieve pain hypersensitivity. Pain, 137, 125137. 
Roeckel, L. A., Utard, V., Reiss, D., Mouheiche, J., Maurin, H., Robé, A., Audouard, E., Wood, J. N., Goumon, Y., Simonin, F., \& Gaveriaux-Ruff, C. (2017). Morphine-induced hyperalgesia involves mu opioid receptors and the metabolite morphine-3-glucuronide. Scientific Reports, 7, 10406.

Romero, A., García-Carmona, J. A., Laorden, M. L., \& Puig, M. M. (2017). Role of CRF1 receptor in post-incisional plasma extravasation and nociceptive responses in mice. Toxicology and Applied Pharmacology, 332, 121-128.

Romero, A., Rojas, S., Cabañero, D., Gispert, J. D., Herance, J. R., Campillo, A., \& Puig, M. M. (2011). A 18F-fluorodeoxyglucose MicroPET imaging study to assess changes in brain glucose metabolism in a rat model of surgery-induced latent pain sensitization. Anesthesiology, 115, 1072-1083.

Romero, A., Romero-Alejo, E., Vasconcelos, N., \& Puig, M. M. (2013). Glial cell activation in the spinal cord and dorsal root ganglia induced by surgery in mice. European Journal of Pharmacology, 702, 126-134.

Romero-Alejo, E., Puig, M. M., \& Romero, A. (2016a). Antihyperalgesic effects of dexketoprofen and tramadol in a model of postoperative pain in mice - effects on glial cell activation. Journal of Pharmacy and Pharmacology, 68, 1041-1050.

Romero-Alejo, E., Puig, M. M., \& Romero, A. (2016b). Inhibition of astrocyte activation is involved in the prevention of postoperative latent pain sensitization by ketamine and gabapentin in mice. Journal of Pharmacology and Pharmacotherapeutics, 7, 22-24.

Rorick-Kehn, L. M., Witcher, J. W., Lowe, S. L., Gonzales, C. R., Weller, M. A., Bell, R. L., Hart, J. C., Need, A. B., McKinzie, J. H., Statnick, M. A., Suico, J. G., McKinzie, D. L., Tauscher-Wisniewski, S., Mitch, C. H., Stoltz, R. R., \& Wong, C. J. (2015). Determining pharmacological selectivity of the kappa opioid receptor antagonist LY2456302 using 
pupillometry as a translational biomarker in rat and human. International Journal of Neuropsychopharmacology, 18, pyu036.

Rorick-Kehn, L. M., Witkin, J. M., Statnick, M. A., Eberle, E. L., McKinzie, J. H., Kahl, S. D., Forster, B. M., Wong, C. J., Li, X., Crile, R. S., Shaw, D. B., Sahr, A. E., Adams, B. L., Quimby, S. J., Diaz, N., Jimenez, A., Pedregal, C., Mitch, C. H., Knopp, K. L., Anderson, W.H., Cramer, J.W., McKinzie, D. L. (2013). LY2456302 is a novel, potent, orally-bioavailable small molecule kappa-selective antagonist with activity in animal models predictive of efficacy in mood and addictive disorders. Neuropharmacology, 77, 131-144.

Rothman, R. B. (1992). A review of the role of anti-opioid peptides in morphine tolerance and dependence. Synapse, 12, 129-138.

Rouwette, T., Vanelderen, P., Roubos, E. W., Kozicz, T., \& Vissers, K. (2012). The amygdala, a relay station for switching on and off pain. European Journal of Pain, 16, 782-792.

Severino, A., Chen, W., Hakimian, J. K., Kieffer, B. L., Gaveriaux-Ruff, C., Walwyn, W., \& Marvizón, J. C. (2018). Mu-opioid receptors in nociceptive afferents produce a sustained suppression of hyperalgesia in chronic pain. Pain, 159, 1607-1620.

Simonnet, G., \& Rivat, C. (2003). Opioid-induced hyperalgesia: Abnormal or normal pain? NeuroReport, 14, 1-7.

Solway, B., Bose, S. C., Corder, G., Donahue, R. R., \& Taylor, B. K. (2011). Tonic inhibition of chronic pain by neuropeptide Y. Proceedings of the National Academy of Sciences of the United States of America, 108, 7224-7229.

Springborg, A. D., Jensen, E. K., Kreilgaard, M., Petersen, M. A., Papathanasiou, T., Lund, T. M., Taylor, B. K., \& Werner, M. U. (2020). High-dose naloxone: Effects by late administration 
on pain and hyperalgesia following a human heat injury model. A randomized, double-blind, placebo-controlled, crossover trial with an enriched enrollment design. PLoS one, 15, e0242169. Springborg, A. D., Jensen, E. K., Taylor, B. K., \& Werner, M. U. (2016). Effects of targetcontrolled infusion of high-dose naloxone on pain and hyperalgesia in a human thermal injury model. Medicine, 95, e5336.

Stone, L. S., MacMillan, L. B., Kitto, K. F., Limbird, L. E., \& Wilcox, G. L. (1997). The $\alpha(2 a)$ adrenergic receptor subtype mediates spinal analgesia evoked by $\alpha 2$ agonists and is necessary for spinal adrenergic-opioid synergy. Journal of Neuroscience, 17, 7157-7165.

Taylor, B. K., Sinha, G. P., Donahue, R. R., Grachen, C. M., Morón, J. A., \& Doolen, S. (2019). Opioid receptors inhibit the spinal AMPA receptor $\mathrm{Ca} 2+$ permeability that mediates latent pain sensitization. Experimental Neurology, 314, 58-66.

Tillu, D. V., Melemedjian, O. K., Asiedu, M. N., Qu, N., De Felice, M., Dussor, G., \& Price, T. J. (2012). Resveratrol engages AMPK to attenuate ERK and mTOR signaling in sensory neurons and inhibits incision-induced acute and chronic pain. Molecular Pain, 8, 5.

Treede, R.D., Rief, W., Barke, A., Aziz, Q., Bennett, M. I., Benoliel, R., Cohen, M., Evers, S., Finnerup, N. B., First, M. B., Giamberardino, M. A., Kaasa, S., Kosek, E., Lavand'homme, P., Nicholas, M., Perrot, S., Scholz, J., Schug, S., Smith, B. H., Svensson, P., Vlaeyen, J.W.S., Wang, S.J. (2015). A classification of chronic pain for ICD-11. Pain, 156, 1003-1007.

Wakisaka, S., Kajander, K. C., \& Bennett, G. J. (1992). Effects of peripheral nerve injuries and tissue inflammation on the levels of neuropeptide Y-like immunoreactivity in rat primary afferent neurons. Brain Research, 598, 349-352.

Walwyn, W. M., Chen, W., Kim, H., Minasyan, A., Ennes, H. S., McRoberts, J. A., \& Marvizón, J. C. (2016). Sustained suppression of hyperalgesia during latent sensitization by $\mu-, \delta-$, and $\kappa-$ 
opioid receptors and $\alpha 2 \mathrm{a}$ adrenergic receptors: Role of constitutive activity. Journal of Neuroscience, 36(1), 204-221.

Wang, D., Raehal, K. M., Bilsky, E. J., \& Sadée, W. (2001). Inverse agonists and neutral antagonists at $\mu$ opioid receptor (MOR): Possible role of basal receptor signaling in narcotic dependence. Journal of Neurochemistry, 77, 1590-1600.

Wang, D., Raehal, K. M., Lin, E. T., Lowery, J. J., Kieffer, B. L., Bilsky, E. J., \& Sadée, W. (2004). Basal Signaling Activity of $\mu$ Opioid Receptor in Mouse Brain: Role in Narcotic Dependence. Journal of Pharmacology and Experimental Therapeutics, 308, 512-520.

Wigerblad, G., Huie, J. R., Yin, H. Z., Leinders, M., Pritchard, R. A., Koehrn, F. J., Xiao, W. H., Bennett, G. J., Huganir, R. L., Ferguson, A. R., Weiss, J. H., Svensson, C. I., \& Sorkin, L. S. (2017). Inflammation-induced GluA1 trafficking and membrane insertion of $\mathrm{Ca} 2+$ permeable AMPA receptors in dorsal horn neurons is dependent on spinal tumor necrosis factor, PI3 kinase and protein kinase A. Experimental Neurology, 293, 144-158.

Zhang, J., Mense, S., Treede, R. D., \& Hoheisel, U. (2017). Prevention and reversal of latent sensitization of dorsal horn neurons by glial blockers in a model of low back pain in male rats. Journal of Neurophysiology, 118, 2059-2069. 